\title{
Plug-in behavior of electric vehicles users: insights from a large-scale trial and impacts for grid integration studies
}

\author{
Felipe Gonzalez Venegas ${ }^{\mathrm{a}, \mathrm{b}, *}$, Marc Petit $^{\mathrm{a}}$, Yannick Perez ${ }^{\mathrm{c}}$ \\ ${ }^{a}$ Université Paris-Saclay, CentraleSupélec, CNRS, Laboratoire de Génie Electrique et Electronique de \\ Paris, 91192, Gif-sur-Yvette, France. \\ ${ }^{b}$ Innovation $\mathcal{E}$ Advanced Technologies Research Division, Stellantis, 78955, Carrières-sous-Poissy, France \\ ${ }^{c}$ Université Paris-Saclay, CentraleSupélec, Laboratoire de Génie Industriel 91190, Gif-sur-Yvette, France.
}

\begin{abstract}
Electric vehicle (EV) grid integration presents significant challenges and opportunities for electricity system operation and planning. Proper assessment of the costs and benefits involved in EV integration hinges on correctly modeling and evaluating EV-user driving and charging patterns. Recent studies have evidenced that EV users do not plug in their vehicle every day (here called non-systematic plug-in behavior), which can alter the impacts of EV charging and the flexibility that EV fleets can provide to the system. This work set out to evaluate the effect of considering non-systematic plug-in behavior in EV grid integration studies. To do so, an open-access agent-based EV simulation model that includes a probabilistic plug-in decision module was developed and calibrated to match the charging behavior observed in the Electric Nation project, a large-scale smart charging trial. Analysis shows that users tend to plug-in their EV between 2 to 3 times per week, with a lower plug-in frequency for large-battery EVs and large heterogeneity in user charging preferences. Results computed using our model show that non-systematic plug-in behavior effects reduce the impact of EV charging, especially for price-responsive charging, as fewer EVs charge simultaneously. On the other hand, non-systematic plug-in can reduce available flexibility, particularly when considering current trends towards larger battery sizes. Counter-intuitively, large-battery fleets can have reduced flexibility compared to small-battery fleets, both in power and stored energy, due to lower plug-in frequency and higher energy requirements per charging session.
\end{abstract}

\footnotetext{
${ }^{*}$ Corresponding author

Email address: felipe.gonzalezvenegas@centralesupelec.fr. Address: CentraleSupelec, 3 rue Joliot Curie, 91190, Gif-sur-Yvette France. (Felipe Gonzalez Venegas)
} 
Improving plug-in ratios of EV users appears as key enabler for flexibility. In comparison, augmenting charging power can increase the flexibility provided by EV fleets but at the expense of larger impacts on distribution grids.

\section{Highlights}

- Agent-based model to generate EV charging profiles considering non-systematic plug-in behavior.

- Plug-in model calibrated with real-world data from a large-scale EV trial.

- Evaluation of non-systematic plug in behavior on EV-grid integration studies.

- Non-systematic plug-in behavior is crucial to assess the impact of EV charging correctly.

- Counter-intuitively, large-battery EVs may provide less flexibility to electricity systems.

Word Count: 7157

14 warnings

Keywords: Electric vehicles, Smart charging, Electricity distribution systems, Charging choices, Vehicle-to-grid 


\section{Nomenclature}

\section{Sets}

$E V$

Set of EVs

$S_{e}$

Set of charging sessions for $\mathrm{EV} e$

\section{Parameters}

$\begin{array}{ll}d_{i} & \text { Daily distance driven for day } i[\mathrm{~km}] \\ \eta & \text { Driving efficiency }[\mathrm{kWh} / \mathrm{km}] \\ \nu & \text { Charging efficiency } \\ b & \text { Battery size }[\mathrm{kWh}] \\ \rho & \text { Range anxiety factor } \\ \alpha & \text { Plug-in preference factor } \\ S o C_{i} & \text { State of Charge at beginning of charging session for day } i \\ \xi_{i} & \text { Required SoC for next day }(i+1) \text { trips } \\ E_{s} & \text { Charged energy in session } s \\ n d_{e} & \text { Number of days of EV } e \text { spent in the Electric Nation trial } \\ n_{e v s} & \text { Number of EVs } \\ A S_{e}(t) & \text { Accessible storage of EV } e \text { at time t } \\ A S_{f} & \text { Average accessible storage of an EV fleet } \\ t s_{\text {avg }} & \text { Average duration of a charging session }\end{array}$




\section{Introduction}

Addressing the climate change challenge requires a drastic reduction of greenhouse gas (GHG) emissions. The transport sector is the second-largest GHG emitter behind the energy sector, accounting for $27 \%$ of total emissions in the European Union (European Environment Agency (2020) ) and 28\% in the US (United States Environmental Protection Agency (2020)) with passenger cars responsible for around half of these emissions. Replacing internal combustion powered vehicles with battery electric vehicles $(\mathrm{EVs})$, if coupled with a low-carbon electricity generation mix, can substantially reduce CO2 emissions while also improving air quality and noise levels in urban areas. Cities and governments worldwide have adopted pro-EV measures, with several countries announcing bans on sales of new petrol/diesel vehicles in the next 10 to 20 years, such as the Netherlands and the UK! by 2030 and France by 2040. These factors have spurred the EV market's rapid growth, with over 2.1 million EVs sold worldwide in 2019 (International Energy Agency (2020)) to more than 3.2 million in 2020 (EV- (2021)). This trend is expected to continue, with projections pointing to over 200 million EVs in the streets by 2030 according to IEA's best-case scenario.

The integration of a large number of EVs into the electricity grid is likely to pose major challenges, especially at the distribution level - medium (MV) and low voltage (LV) grids where they will be connected. Additional load due to EV charging could overload grid assets or create voltage issues, in both cases requiring substantial investments in new infrastructure (Gonzalez Venegas et al. (2021)). However, EVs can be controllable resources and can provide flexibility to the grid, via unidirectional (smart charging) or bidirectional (V2G) charging. EV flexibility can reduce the impacts of grid integration and create value for end-users and the electricity system by providing services such as frequency regulation or increasing renewable generation hosting capacity (Thompson and Perez (2020)).

A proper assessment of the impacts and flexibility potential of EVs requires appropriate consideration of EV driving and charging behavior. Most studies consider a plug-in behavior here called 'systematic', meaning that the EVs are plugged in every day, but regular private users do not follow this pattern even if they have easy access to a charging point, such as at

\footnotetext{
${ }^{1}$ The UK ban concerns pure combustion engines by 2030 and plug-in hybrids by 2035 .
} 
home (Western Power Distribution (2019), Helmus et al. (2020)).

The objective of this work is to quantify the impact of non-systematic plug-in behavior (i.e. not plugging in every day) on EV-grid integration studies. To achieve this we developed a probabilistic decision model for EV plug-in behavior and calibrated it with real-world data to match observed behavior of EV users. Then, we analyzed the impact of non-systematic plug-in behavior on additional EV peak load into the grid and on the potential of EV fleets to provide flexibility.

Main results from this work show that it is important to consider realistic non-systematic plug-in behavior to correctly assess the impacts of EV charging, especially at the distribution level and when considering price-responsive (smart) charging. As well, considering systematic (every day) charging can largely overestimate the flexibility that EV fleets can provide to the system via smart charging and V2G, both in terms of power $(\mathrm{kW})$ and storage $(\mathrm{kWh})$ available to aggregators. Non-systematic plug-in effects are more important for large-battery EVs, both in terms of impact of EV charging and on available flexibility. Counter-intuitively, large-battery EV fleets can put flexibility aggregators at risk, as they offer lower flexibility potential due to lower plug-in frequency and less flexible time per charging session.

We anticipate this work to bring valuable insight to several stakeholders: distribution system operators, EV aggregators, regulators, and car manufacturers. It provides insights into the impacts of EV charging on distribution systems and the real potential that smart charging and V2G can offer to the electricity system, considering evolutions in battery sizes and charger power, and end-user behavior.

The paper is organized as follows. Section 2 analyzes relevant work on plug-in behavior modeling. Section 3 describes the proposed agent-based model for simulating EV charging, including the plug-in decision module. Section 4 provides insights on plug-in behavior from the a large-scale EV trial, which we use to calibrate our model. Section 5 evaluates the impact of considering non-systematic plug-in behavior in EV grid integration and flexibility studies. Finally, Section 6 reports the conclusions of the paper and provides leads for further research. 


\section{Literature review on plug-in behavior}

Most EV grid integration studies analyzing grid impacts of EV charging and the potential of smart charging and V2G as flexibility sources consider a systematic plug-in behavior. EV impact studies include Salah et al. (2015) who analyzed the impacts of uncontrolled and price-responsive charging at $\mathrm{HV} / \mathrm{MV}$ substation level in Switzerland, and Veldman and Verzijlbergh (2015) that studied the impacts of EV integration in the MV grid in the Netherlands. These studies showed that price-responsive charging can create larger constraints in the grid due to the synchronization of EV charging at low-price hours. Muratori (2018) quantified the demand increase using detailed EV and household modeling based on US data, and similarly Guo et al. (2020) analyzed the peak load created by EV charging at different aggregation levels. In Leemput et al. (2015), authors that studied the impacts of EV integration on Belgian LV grids, and Gaete-Morales et al. (2020) developed a tool for generating EV charging profiles. All previous studies consider that EVs are plugged in every day.

The literature on EV flexibility includes Bartolini et al. (2020) who analyzed the potential of increasing self-consumption in a PV-rich Italian village using V2G-capable EVs, with underlying assumption that EVs are plugged in every day and at all times (day and night) that they are not being driven, which can prove to be highly unrealistic. In another case study, Borne et al. (2018) and Calearo and Marinelli (2020) estimated the revenues of EV fleets participating in primary frequency regulation services every day. This hypothesis may be possible for highly reliable company fleets, but is less accurate for much more uncertain private user fleets.

Analysis using real EV driving and charging behavior datasets have shown that users do not recharge every day even if they have access to charging infrastructure (Western Power Distribution (2019) $)$, and that there is large heterogeneity among EV users charging patterns (Philipsen et al. (2018); Zoepf et al. (2013); Schäuble et al. (2017)). The Electric Nation project in the UK, which counted over 600 participants running different makes and models, including plug-in hybrid EVs (PHEV), range extenders (REX) and battery EVs (BEV), and at-home charge access, showed a median charging frequency of 3.64 times per week for all participants, and only 2.73 times per week for BEV users (Western Power Distribution 
(2019)). Similar results have been found in Dutch public charging infrastructure, where Helmus et al. (2020) identified typologies of EV users from a dataset consisting of over 28000 unique users and computed an average charging frequency for different EV user types of between 0.9 and 4.6 events per week.

Thus, considering a systematic (i.e. every day) charging behavior can provide biased estimations of the grid impacts of EV charging and significantly overestimate the flexibility potential of each charging session. As users only plug in their EV a few times per week, there are fewer EVs available (i.e. connected) to provide flexibility to the system.

Studies have found that the main factors that affect the plug-in decision (whether to connect or not the EV) when charging at the users' regular charging location are expected kilometers to be driven in the next trip and the remaining range (Sun et al. (2015), Daina et al. (2017)), while still maintaining a 'comfortable range' buffer (Franke and Krems (2013) $)$. Recent studies have started to consider and model the non-systematic plug-in behavior of EV users, summarized in Table 11. Still, most do not consider all the factors that shape plug-in behaviors.

A study done by the French transmission system operator RTE considered different levels of non-systematic plug-in to evaluate EV charging impacts and the potential to provide flexibility services at the transmission level, though only by defining different shares of EVs connected per day at the national level $(\overline{R T E}(\overline{2019}))$. Plug-in behavior was explicitly modeled by Calearo et al. (2019) to analyze the impact of $24 \mathrm{kWh}$ EVs on a LV grid using predefined plug-in probability curves based on user's daily distances driven and EV state of charge $(S o C)$ on arrival at home. Bollerslev et al. (2021) extended this work to $48 \mathrm{kWh}$ and $60 \mathrm{kWh}$ EVs, but without data supporting this extrapolation, and studied the coincidence factors of uncontrolled EV charging at different aggregation levels. Using the same models, González-Garrido et al. (2019) studied the gains of optimal charging scheduling in the Danish island of Bornholm considering $40 \mathrm{kWh}$ EVs with non-systematic charging behavior. However, there is no parametric model for the probability curves used by these papers, limiting their use in other studies and the extrapolation to different battery sizes. Bouallaga and Doumbia (2019) proposed a fuzzy logic plug-in decision model that depended on EV battery size and SoC on arrival at the charging location to evaluate the impact of EV charg- 
ing at a $\mathrm{HV} / \mathrm{MV}$ substation in Paris. However, no data was supporting this model. Fischer et al. (2019) analyzed EV impact on residential load profiles considering a plug-in decision model based on a logistic function dependent exclusively on SoC on arrival. The parameters that define the logistic function can be made to vary to account for the heterogeneity in user charging behavior. Dixon et al. (2020) proposed a heuristic model that selects the minimum number of charging events to cover all trips during a full week by minimizing the inconvenience of EV charging. Dixon and Bell (2020) then applied this model to evaluate the impacts of EV charging in distribution networks, considering different levels of charger power and battery sizes, and Dixon et al. (2020) analyzed the potential for mitigating wind curtailment comparing the minimal charging strategy to a systematic (every day) charging. Gonzalez Venegas et al. (2019) proposed a deterministic model where users plug in only when needed for the next day while keeping a 'safety' buffer (or range anxiety factor). They used this model to evaluate EV impact on HV/MV substations on a weekly basis, finding that a significant share of EV charging could be displaced to weekends and that both battery sizes and rural/urban conditions can modify these charging patterns. Gonzalez Venegas et al. (2020) extended their deterministic model to a probabilistic model and used the EV load and availability profiles to analyze the participation of V2G-capable EV fleets in local flexibility tenders. Results showed that fleets with non-systematic plug-in behavior obtained revenues at least 2-fold lower (and up to 7 -fold lower) than fleets with systematic charging, due to EVs not being plugged-in at times when flexibility was required. 
Table 1: Summary of main EV grid integration studies that consider non-systematic plug-in behavior.

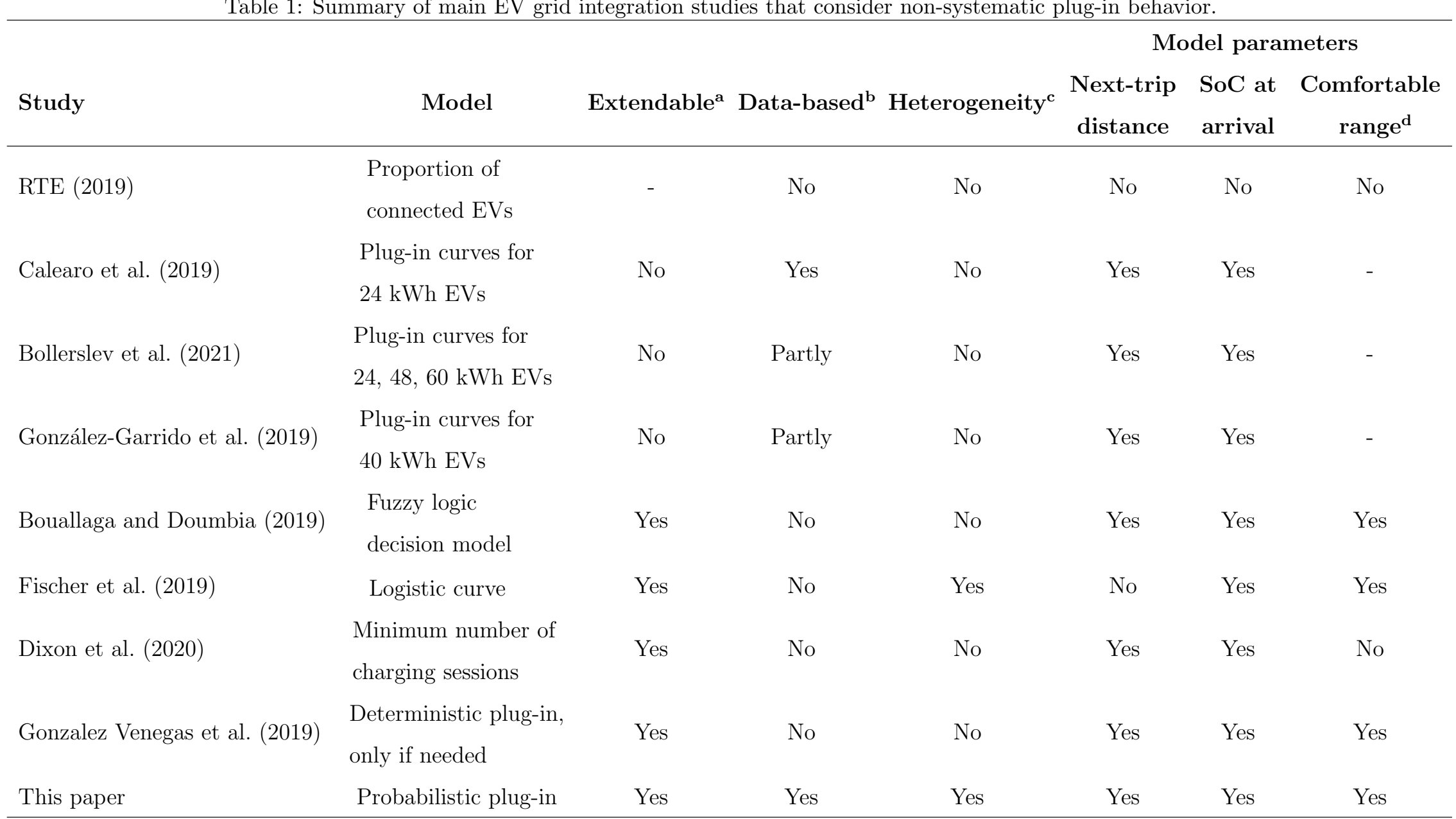

a A model that can be applied to other contexts or EVs with different characteristics.

b A model that is supported by real-world data of EV usage.

c A model that allows for heterogeneity on EV users plug-in preferences.

$\mathrm{d}$ The comfortable range refers to the consideration of a buffer with respect to the uncertainty of next-day trips. It can be interpreted as a risk aversion towards running out of battery. 
We find that despite the evidence from various demonstrator projects and EV usage analyses, most EV-grid integration literature still does not consider the non-systematic plugin behavior of users. Some recent studies have started to consider and model non-systematic plug-in patterns, but either the models are not readily extendable to different kinds of users or EV characteristics (e.g., only applicable to a given battery size), or they do not account for the heterogeneity of user charging preferences (all users behaving the same), or the decision models are not backed up by real-world data on EV user plug-in behavior. Furthermore, there has not been any study that specifically analyzes the impact of considering the nonsystematic plug-in behavior in EV grid integration studies.

This work aims to bridge the gaps identified in the literature by developing an advanced plug-in decision model and then explicitly analyzing the impact of non-systematic plug-in behavior on EV-grid integration studies. The model is extendable to different situations and usages, it can account for the heterogeneity of user's plug-in preferences, and it is calibrated using real EV usage data obtained from a large-scale EV trial.

\subsection{Contributions}

The main contributions are the following:

- First, we propose an ABM for EV simulation that considers non-systematic plugin behavior. In particular, the plug-in decision complies with several characteristics missing from the scientific literature: it is extendable, can capture heterogeneity, and is backed-up by real-world data.

- Second, we provide insights on plug-in preferences from EV users using a large-scale dataset that comprises a wide diversity of EV marks and models. This is of particular interest as most analysis come from have little diversity on EV characteristics (see for example Quirós-Tortós et al. (2016); Neaimeh et al. (2015); Boston and Werthman (2016); Schäuble et al. (2017)).

- Third, we explicitly evaluate the impact of non-systematic plug-in behavior on EV grid integration studies, in both impact of EV charging and flexibility potential of EV fleets. To the best of our knowledge, this analysis has not been previously carried out. 


\section{EV simulation model}

\subsection{Model}

We developed a stochastic agent-based tool to generate weekly or monthly EV load curves for distribution system studies that considers charging at one regular location, such as home charging. Agent-based models are widely used to simulate EV-grid interactions as they allow to simulate each EV individually, allowing each agent to interact with its environment and make its own decisions (see, for example, Lin et al. (2019) for EV charging at various locations, Marmaras et al. (2017) for electricity grid and road transport interactions, or Olivella-Rosell et al. (2015) for a study of EV charging impact at distribution level). The model proposed here consists of three sequential sub-modules: a mobility module, a plug-in decision module, and a charging module that runs for each EV in each day of simulation, as shown in Fig 1. The model is available in https://github.com/fgonzalezvenegas/ EVModel.

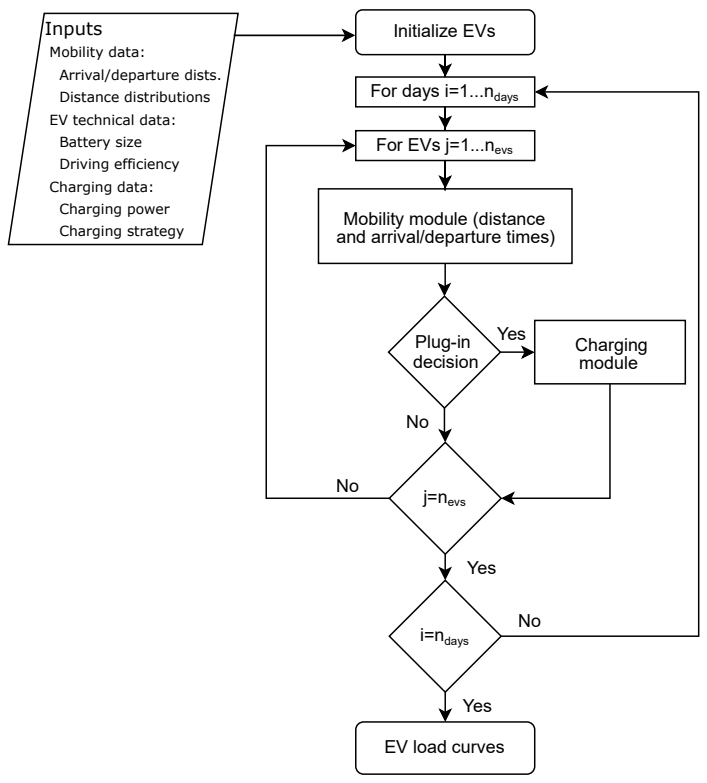

Figure 1: Flowchart of the proposed model

The mobility module computes daily distance driven $\left(d_{i}\right)$ and arrival and departure times at the EV charging location. It simulates commuters that travel the same distance to work every weekday and make variable trips on weekends, with the possibility to include additional trips to increase the variability of daily distances driven. Arrival and departure times are 
randomly sampled from user-defined probability distributions for each day. Finally, $S o C$ levels on arrival at the charging location are computed based on distance driven, EV driving efficiency $(\eta$ in $\mathrm{kWh} / \mathrm{km})$ and battery size ( $b$ in $\mathrm{kWh})$, as shown in in Eq. 1.

$$
S o C_{i}=S o C_{i-1}-\frac{d_{i} \cdot \eta}{b}
$$

Second, the plug-in module determines the plug-in decision of the EV agent"2, The plugin decision is based on three factors identified in the literature, i.e., a range anxiety factor or comfortable range $(\rho)$, the expected next-trip distance $\left(d_{i+1}\right)$, and $S o C$ at arrival, and detailed in Eqs. 2 and 3 . The user will plug in if the remaining range (i.e., $S o C$ on arrival) is lower than what is required for the next trip after allowing for a range anxiety safety margin $\left(\xi_{i}\right)$ ), otherwise the probability of plugging in decreases with higher $S o C$ levels. The $\alpha$ parameter modifies the user's plug-in preference, thus allowing to account for the heterogeneity of user choices. For $\alpha$ values close to zero, the user will plug in only if they need to cover next-day trips, whereas for high $\alpha$ values $(\alpha>>1)$ the user will tend to plug in every day. Fig. 2 gives an illustrative example of these plug-in probability curves.

$$
\begin{aligned}
& \xi_{i}=\frac{d_{i+1} \cdot \eta}{b} \cdot \rho \\
& \mathbb{P}\left(\text { plugin }_{i}\right)=\left\{\begin{array}{lcc}
\text { if } & S o C_{i} \leq \xi_{i}: & 1 \\
\text { if } & S o C_{i}>\xi_{i}: & 1-\left(\frac{S o C_{i}-\xi}{1-\xi}\right)^{\alpha}
\end{array}\right.
\end{aligned}
$$

Finally, if the agent decides to recharge the vehicle, the charging module will compute the charging profile needed to reach the desired SoC. Different charging strategies have been implemented, including uncontrolled charging, off-peak charging, and charging-cost minimization with dynamic tariffs. In this study, we focus on uncontrolled charging and price-responsive charging.

\footnotetext{
${ }^{2}$ This model is a probabilistic extension of the deterministic module proposed in Gonzalez Venegas et al. $(2019)$
} 


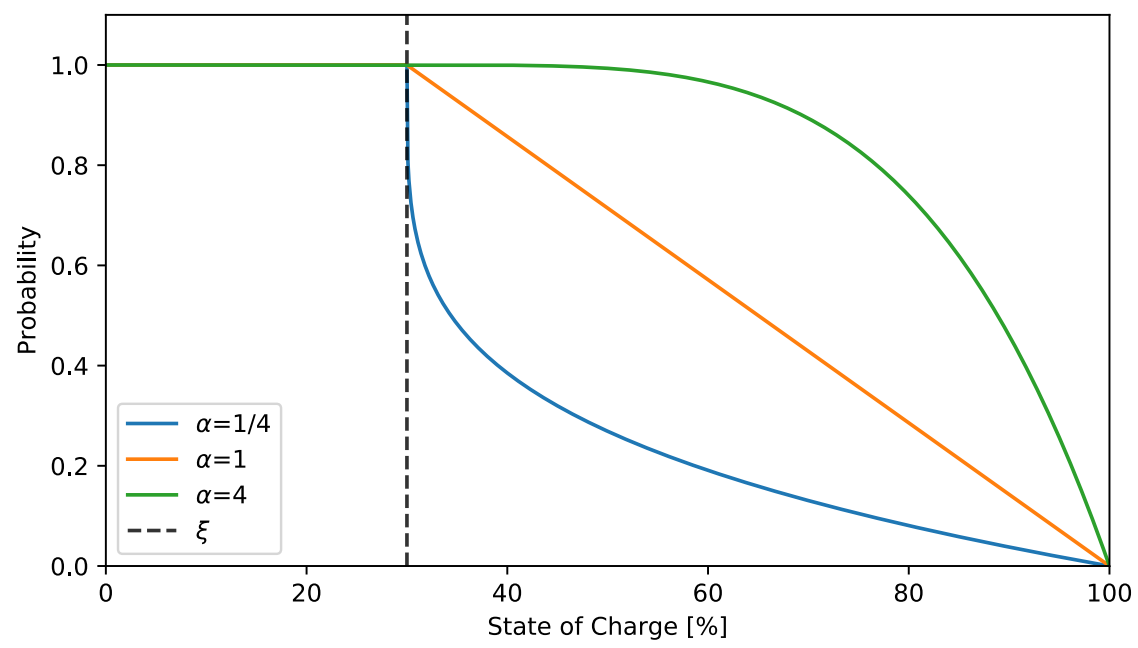

Figure 2: Plug-in probability curve according to $S o C$ at arrival for three plug-in preferences $(\alpha)$, and for a required $S o C$ for next trip $(\xi)$ of $30 \%$

\section{Insights from a large-scale EV trial and model calibration}

\subsection{The Electric Nation trial}

We used real-world data from the Electric Nation project to calibrate the plug-in decision module. The Electric Nation project was a large-scale smart charging trial in the UK that ran from 2016 to 2018. The full dataset contains information for 153621 charging sessions, including starting time, ending time, and energy consumed for each session, by 601 unique users with a variety of BEVs, PHEVs, and REX brands and models $3^{3}$

To calibrate the model, we only considered BEV users that stayed in the trial for more than 3 months. After cleaning the dataset, we obtained 52822 charging sessions for 265 unique users, encompassing a wide range of EV brands and battery sizes, as shown in Fig. 3. However, there were two distinct EV groups: the first composed of small EVs with battery sizes between 20-35 kWh, and a second group composed of large EVs with battery sizes around $75 \mathrm{kWh}$ represented mainly by Tesla cars as shown in Table 2 .

\footnotetext{
${ }^{3}$ Dataset available at Western Power Distribution (2019)
} 
Table 2: Most popular BEVs in the Electric Nation trial (out of 265)

\begin{tabular}{lcc}
\hline EV Model & Users & Battery size $[\mathbf{k W h}]$ \\
\hline Nissan Leaf & 79 & $24-30$ \\
Tesla Model S & 74 & 75 \\
BMW i3 & 43 & 33 \\
Tesla Model X & 20 & $75-100$ \\
Kia Soul EV & 18 & $27-30$ \\
Renault Zoé & 12 & 24 \\
\hline
\end{tabular}

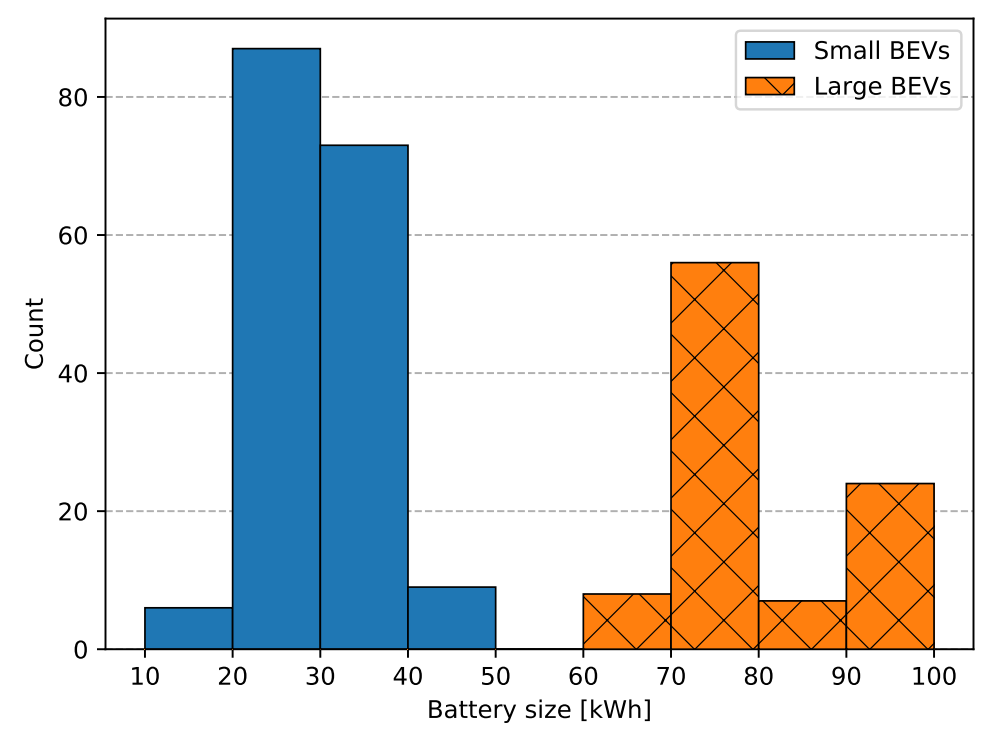

Figure 3: Distribution of battery sizes in the Electric Nation trial

For each $\mathrm{EV}$ user $e$, we computed three charging behavior indicators: the average number of weekly charging sessions, the average charged energy per session, and the average daily distance driven $\left(\right.$ davg $\left._{e}\right)$. As the dataset does not provide the actual driven distances, we estimated them from the charged energy $(E)$, as shown in Eq. 4. For this we considered a charger efficiency $(\nu)$ of $95 \%$ and a driving efficiency $(\eta$, in $\mathrm{kWh} / \mathrm{km})$ dependent on the battery size, shown in Eq. 5 (from Weiss et al. (2020)). 


$$
\begin{gathered}
\operatorname{davg}_{e}=\frac{1}{n d_{e}} \sum_{s \in S_{e}} \frac{E_{s} \cdot \nu}{\eta_{e}} \\
\eta_{e}=\left(14+0.09 \cdot b_{e}\right) / 100
\end{gathered}
$$

The charging behavior indicators for all users are shown in Fig. 4, and mean and median values are shown in Table 3. Despite the large heterogeneity in charging preferences, some trends can be identified. Large EVs are plugged in less often (mean frequency of 2.79 sessions per week) than small EVs (mean frequency of 3.31 sessions per week) and charge a higher amount of energy per session (left-hand plot in 4), as larger battery sizes allow for longer periods without requiring to recharge. Furthermore, users who drive higher distances per day tend to plug in their car more frequently, and users with higher battery capacity drive longer distances for the same frequency of charging sessions (right-hand plot in Fig. 4). This means that a small-EV user who plugs in 4 times a week will drive around $40 \mathrm{~km} /$ day, whereas a large-EV user will drive $60 \mathrm{~km} /$ day for the same charging frequency. A linear regression model between charging sessions and daily distances, disaggregated by large and small EVs, shows that an increase in daily distance driven of $7 \mathrm{~km}$ for small EVs and $13.9 \mathrm{~km}$ for large EVs requires one extra charging session per week. Note that the aggregated fleet can be seen as representative of car usage in Europe, where daily distances driven are around 40 km/day (similar results are found in Borne (2019) for France, González-Garrido et al. (2019) for Denmark or Van Roy (2015) for Belgium). Driven distances can be considered high for UK standards, where average yearly mileage in 2019 was around 10,000 km ( $30 \mathrm{~km} /$ day) (Department for Transport (2020)).

\subsection{Plug-in decision model calibration}

We calibrate our model to match the average plug-in frequency found in the Electric Nation trial for three cases representative of small, average-size (given by average values across the whole dataset), and large EV fleets. Using the EV model presented in Section 3, a simulation for 1,000 EVs and 12 weeks was carried out with a range anxiety factor $(\rho)$ of 1.5 , as in Gonzalez Venegas et al. (2019), and for levels of the plug-in parameter $(\alpha)$ varying from $10^{-2}$ to $10^{2}$. Each simulated EV has a daily distance sampled from a lognormal distribution, 


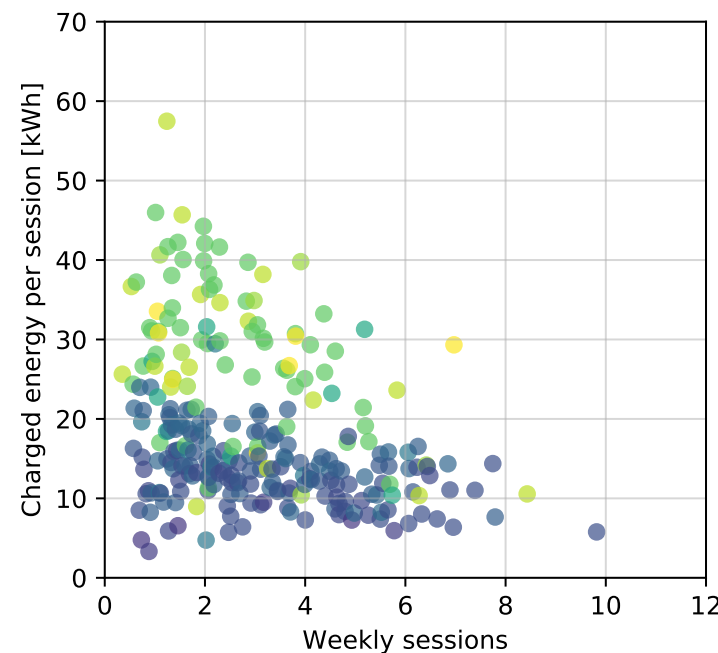

(a)

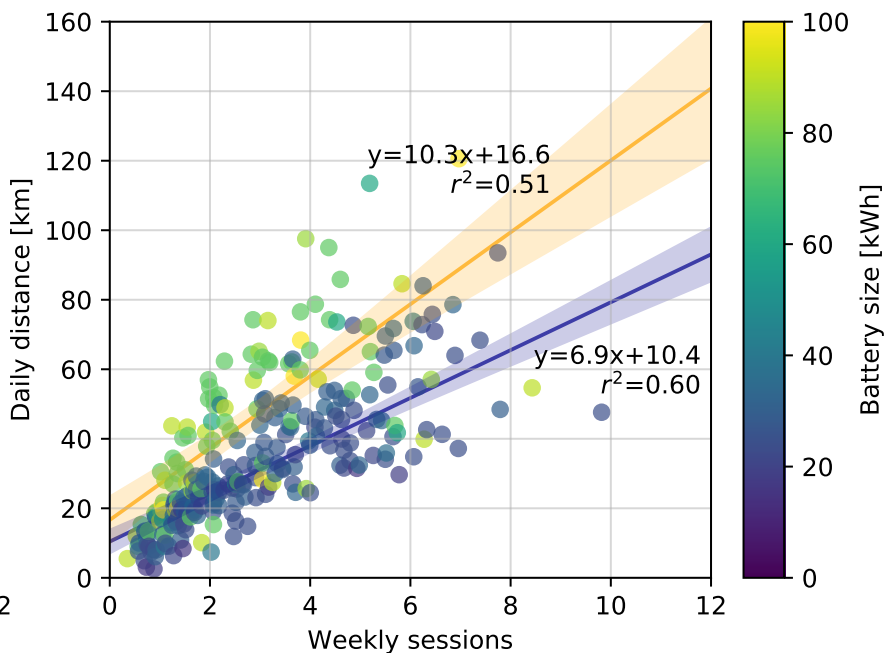

(b)

Figure 4: Charging behavior indicators for EV users in the Electric Nation trial: (a) Average charged energy per session and (b) average daily distance driven $\left(d_{\text {avg }}\right)$ according to weekly charging sessions. Each point corresponds to an EV user. Panel (b) includes linear regressions between weekly charging sessions and daily distance for small and large EVs, shaded areas corresponding to the confidence interval at $95 \%$ of the linear regression.

Table 3: Charging behavior indicators of EV users from the Electric Nation trial. Results are shown for the aggregate EV user population and disaggregated for small ( $<50 \mathrm{kWh}$ battery) and large ( $>50 \mathrm{kWh}$ battery) EVs.

\begin{tabular}{lcccccc}
\hline \multirow{2}{*}{ Indicator } & \multicolumn{3}{c}{ Mean } & \multicolumn{3}{c}{ Median } \\
& All & Small & Large & All & Small & Large \\
\hline $\begin{array}{l}\text { Weekly sessions } \\
\text { Charged energy }\end{array}$ & 3.12 & 3.31 & 2.79 & 2.72 & 3.00 & 2.28 \\
$\begin{array}{l}\text { per session [kWh] } \\
\text { Daily distance [km] }\end{array}$ & 38.5 & 13.2 & 28.3 & 15.2 & 13.2 & 29.3 \\
\hline
\end{tabular}


as in Borne (2019). Table 4 shows the main parameters of the simulations used to calibrate the model, and Fig. 5 shows the average frequency of charging sessions for a sweep of the $\alpha$ parameter for the three cases and the selected $\alpha$ value to match the observed data. The selected $\alpha$ parameter ranges between 0.89 for small EVs, to 1.31 for the average fleet.

Table 4: Simulation parameters for the three representative cases to calibrate the $\alpha$ parameter.

\begin{tabular}{lccc} 
EV case & $\begin{array}{c}\text { Battery size } \\
{[\mathbf{k W h}]}\end{array}$ & $\begin{array}{c}\text { Average daily } \\
\text { distance }[\mathrm{km}]\end{array}$ & $\begin{array}{c}\text { Average weekly } \\
\text { plug-in frequency }\end{array}$ \\
\hline Small & 28 & 33.3 & 3.31 \\
Average & 46 & 38.1 & 3.12 \\
Large & 79 & 46.7 & 2.79 \\
\hline
\end{tabular}

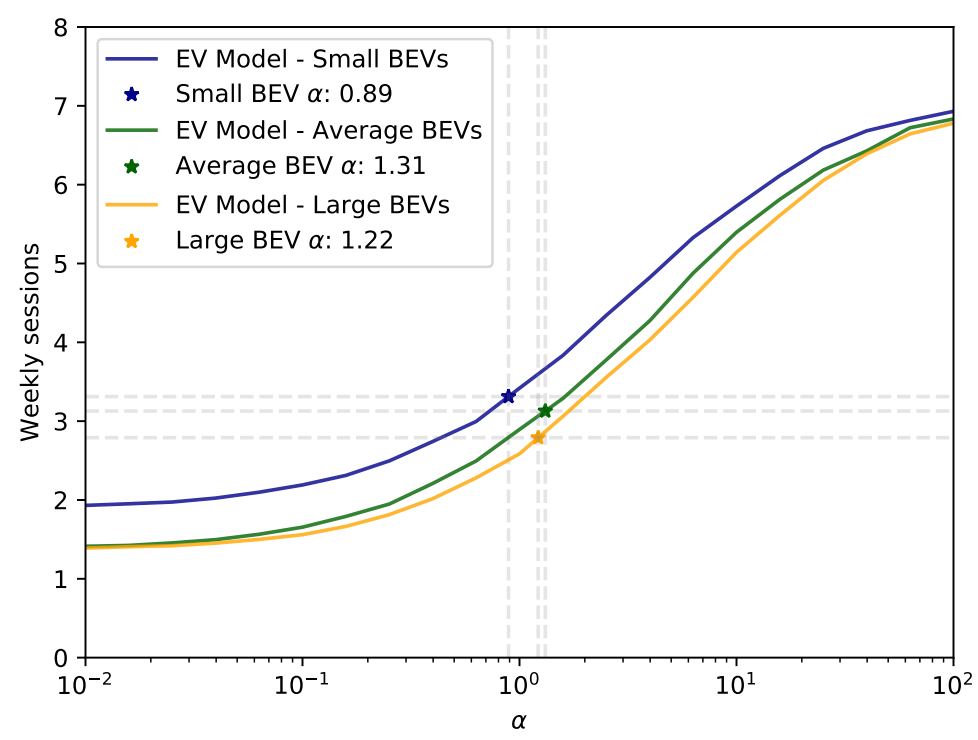

Figure 5: Average weekly charging frequency from EV model simulations varying the $\alpha$ parameter. $\alpha$ is selected to match the average charging frequency observed in the Electric Nation trial.

To verify the quality if the model calibration, we computed the same charging behavior indicators for the three simulated EV cases. We considered the heterogeneity of users' charging choices by sampling the $\alpha$ value individually for each user using a lognormal distribution 
centered on the $\alpha$ values previously found 4 We used a lognormal distribution due to the logarithmic behavior of the $\alpha$ variable (see Fig. 5). For each EV group, the underlying normal distribution of the lognormal function has a mean $(\mu)$ equal to $\log \alpha$ and standard deviation $(\sigma)$ of one $5^{5}$ The charging behavior indicators of the simulations, shown in Fig. 6, are similar to those observed in the trial, both qualitatively and quantitatively. The simulations reproduce the same EV-group patterns that in the trial (lower charging frequency, higher energy per session, and higher distances driven for large EVs), including a large heterogeneity on charging choices. A group of users with significantly higher charged energy per session and a low charging frequency is also found that was not observed in the homogeneous case (see left-hand plot). Quantitatively, the linear regression models of daily distances vs. charging frequency for small and large EV groups present similar coefficients to those observed in the trial, thus demonstrating the validity of the model calibration.

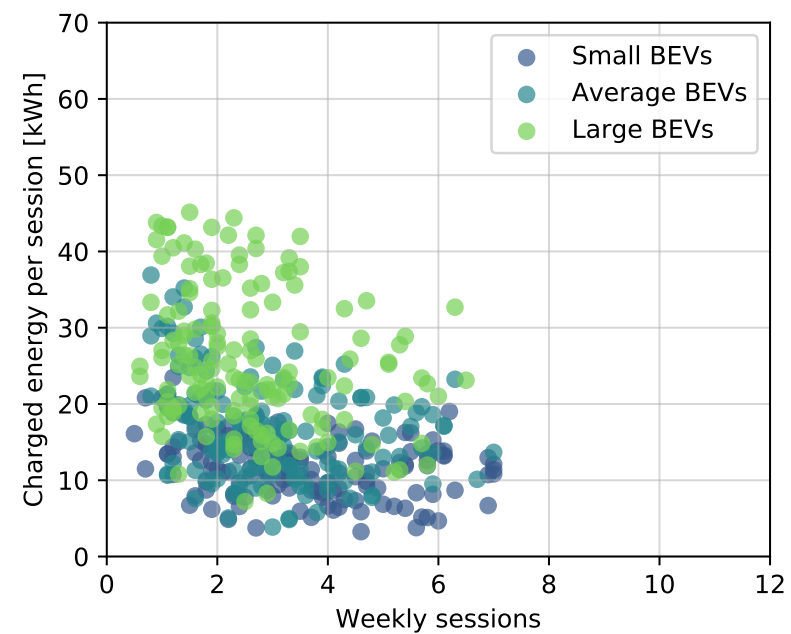

(a)

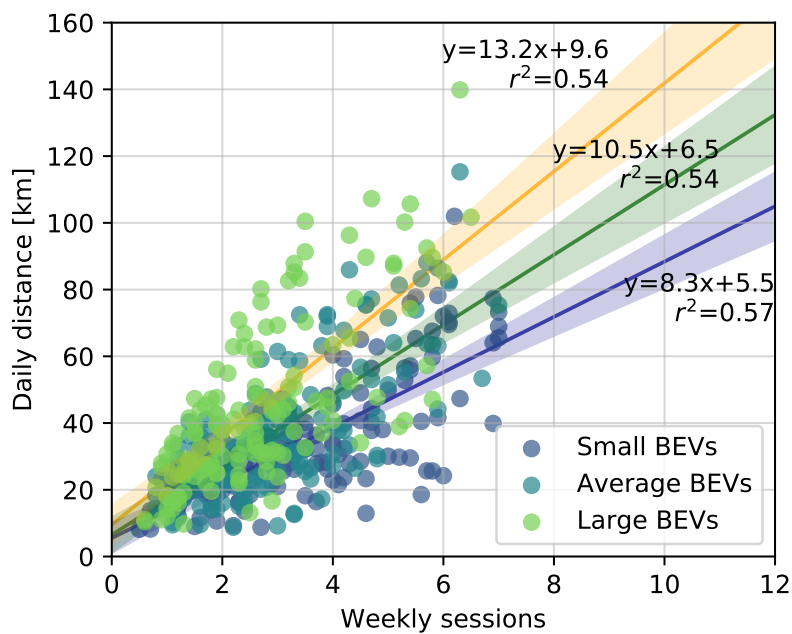

(b)

Figure 6: Charging behavior indicators for heterogeneous $\alpha$ simulation: (a) Average charged energy per session and (b) average daily distance driven $\left(d_{\text {avg }}\right)$ according to weekly charging sessions. Each point corresponds to an EV user. Panel (b) includes linear regressions between weekly charging sessions and daily distance for small and large EVs, shaded areas corresponding to the confidence interval at $95 \%$ of the linear regression.

\footnotetext{
${ }^{4}$ Initially, an homogeneous case was studied, where all EVs had the same $\alpha$ value. Results for this case can be found in the Appendix.

${ }^{5}$ For a lognormal distribution centered in $x$, the underlying normal distribution has a $\mu$ of $\log (x)$
} 
The EV model with heterogeneous plug-in choices can easily be applied to analyze the charging behavior of EV users under different driving and charging conditions. Fig. 7 shows the plug-in frequency for an urban case with low daily distances driven $\left(d_{\text {avg }}\right)$ and a rural case with high $d_{\text {avg }}$, and for varying battery sizes, based on Gonzalez Venegas et al. (2019). Results show that plug-in frequency decreases with increasing battery sizes. In the average scenario, over $75 \%$ of $25 \mathrm{kWh}-\mathrm{EV}$ users plug-in more than 3 or more times per week, compared to only $25 \%$ of users with $100 \mathrm{kWh}$ EVs. This effect is exacerbated under urban conditions where daily mobility requirements are lower, with less than $25 \%$ of $50 \mathrm{kWh}$-battery users plugging in 3 or more times per week. Conversely, in rural areas where daily mobility requirements are higher, users will tend to plug-in more often, with a significantly higher share of users plugging in almost daily. These effects can be of great interest to flexibility aggregators that rely on EVs being plugged in to provide services to the grid, as will be discussed in the next Section, as well as for public charging infrastructure planning authorities that need to determine and map out a sufficient coverage of charging points.

These results can provide insights on EV charging under evolution of mobility patterns. For example, a reduction in driven distances as advocated by Committee on Climate Change (2020) or Bigo (2020) can entail a reduction the plug-in ratios of EV users.

\section{Impact of non-systematic plug-in behavior on EV grid integration studies}

We evaluated the impact of considering non-systematic plug-in behavior in EV grid integration studies. For this purpose, we analyzed two aspects: the impact of EV charging in power systems through the peak load created by EV fleets, and the flexibility potential to assess the time and accessible storage capacity that EV fleets can use for smart charging or V2G-based flexibility services.

Simulations using the EV model were carried out for a fleet of 10,000 EVs and combinations of battery size, charging power, plug-in behavior, and charging strategies. We considered three battery sizes, i.e., small $(25 \mathrm{kWh})$, medium $(50 \mathrm{kWh})$ and large $(75 \mathrm{kWh})$ in line with current trends, and three charging power levels, i.e., $3.7 \mathrm{kVA}$ and $7.4 \mathrm{kVA}$, reflecting standard single-phase chargers, and an $11 \mathrm{kVA}$ three-phase charger, all with a 0.95 power factor. Charging choices were considered via systematic plug-in (i.e., every day) and 


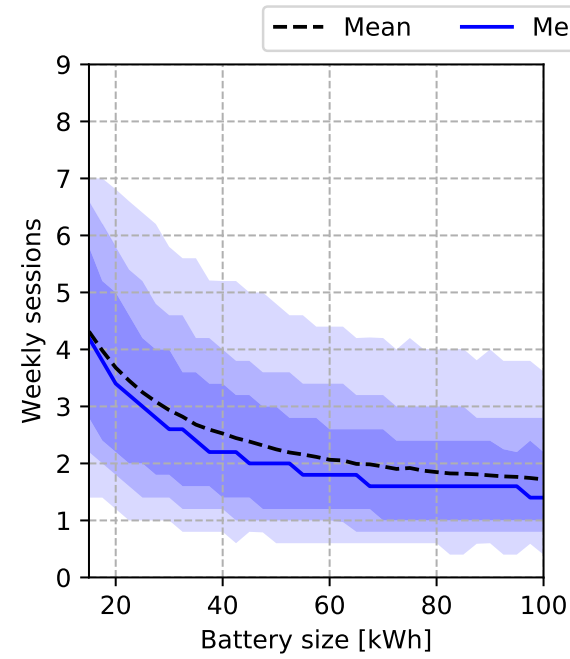

(a) Urban

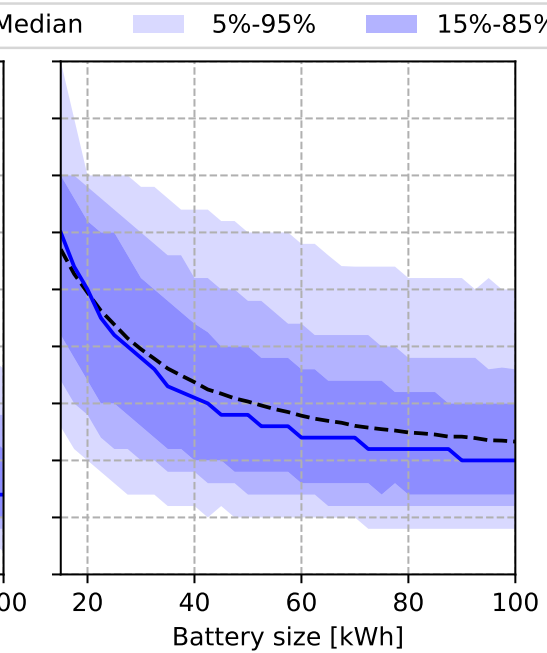

(b) Average

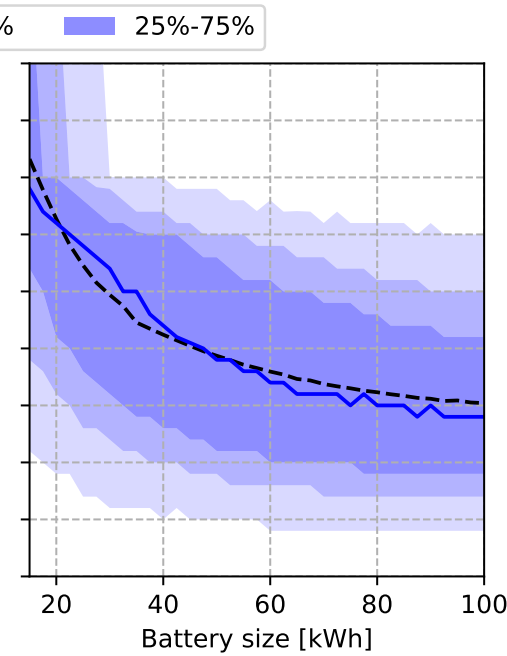

(c) Rural

Figure 7: Charging frequency distribution for varying battery sizes for (a) urban ( $\left.d_{\text {avg }} 22.2 \mathrm{~km}\right)$, (b) average $\left(d_{\text {avg }} 38.9 \mathrm{~km}\right)$, and $(\mathrm{c})$ rural $\left(d_{\text {avg }} 70.6 \mathrm{~km}\right)$ cases. EV model simulations with heterogeneous plug-in behavior, median $\alpha 1.31$.

three non-systematic plug-in behaviors, an average case given by the calibration with the Electric Nation trial $(\alpha=1.31)$, a high plug-in case $(\alpha=3.4)$, and a low plug-in case $(\alpha=0.5)$ to account for different charging choices. Two charging strategies were analyzed: uncontrolled charging, where EVs are charged as soon as they are plugged in, and price-responsive smart charging, where EVs charge during an off-peak period between $10 \mathrm{pm}$ and 6 am ${ }^{6}$, Finally, arrival and departure times at the charging locations are given by joint probability distributions derived from the Electric Nation trial (probability distributions shown in 8).

\subsection{Impact on peak load}

To quantify the impact of EV charging at different levels of the grid, peak load was computed for fleets of varying sizes between 1 and 10,000 EVs, as the impact of EV charging at LV feeder level (tens of EVs) will not be the same as in the LV transformer (up to hundreds of $\mathrm{EVs}$ ) or $\mathrm{HV} / \mathrm{MV}$ substation (hundreds to thousands of EVs). 500 iterations for each fleet size were carried out to obtain statistically significant results, and the average EV peak load

\footnotetext{
${ }^{6}$ This can be seen as a worst-case scenario where the the diversity of EV charging is lost. However, this can potentially happen if end-user tariffs in a pocket of the grid are the same.
} 


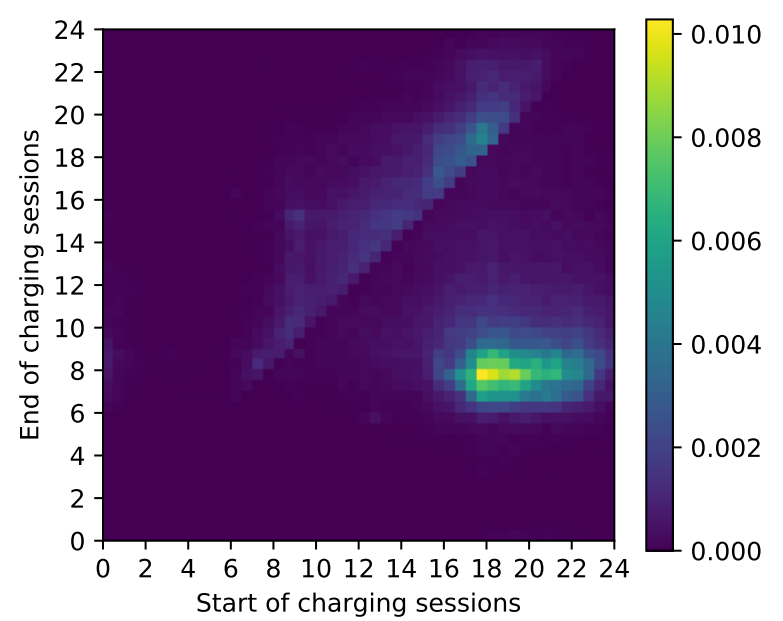

(a) Joint distribution

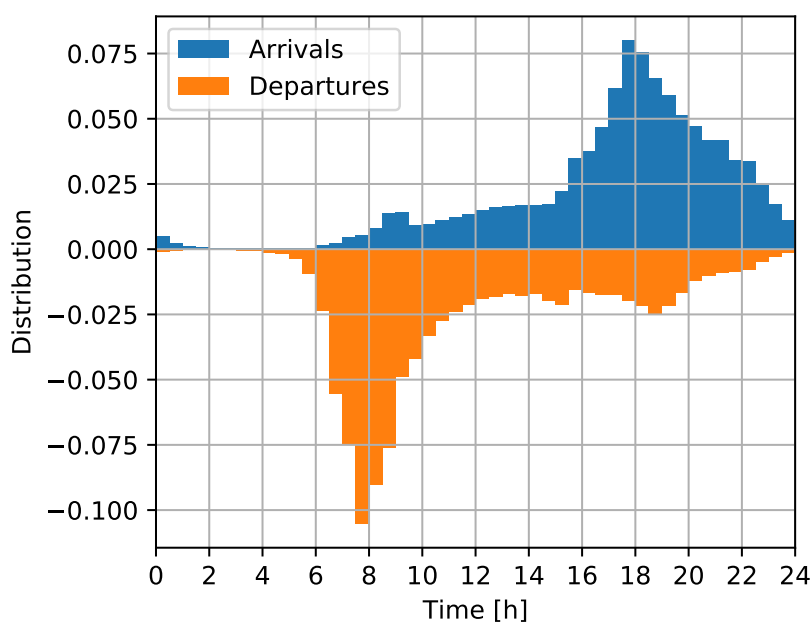

(b) Marginal distribution

Figure 8: (a) Joint probability distribution and (b) marginal distribution for arrival and departure times derived from the Electric Nation trial.

is reported. This approach follows the studies of Guo et al. (2020) and Bollerslev et al. (2021) on coincidence factors of uncontrolled EV charging 7 , and extends this analysis to the case of price-responsive smart charging.

Results for the uncontrolled case, depicted in Fig. 9, show the decreasing coincidence of EV charging as EV fleet sizes increase due to the natural diversity of charging sessions, both in start times and in energy requirements. This effect is higher for higher charger power, as each charging session requires less time, and thus there is less coincidence in EV charging, with a drastic drop in $11 \mathrm{kVA}$ chargers for fleets above $7 \mathrm{EVs}$. The coincidence factor of EV charging, summarized in Table 5, reaches 70\% for fleets of 10 EVs (LV feeder level) with $3.7 \mathrm{kVA}$ chargers but only $21 \%$ for fleets of $10,000 \mathrm{EVs}$ (HV/MV substation level). The coincidence factor decreases as charging power increases, reaching only $12 \%$ for a $7.4 \mathrm{kVA}$ charger $(0.9 \mathrm{~kW} / \mathrm{EV})$ and $9 \%$ for an $11 \mathrm{kVA}$ charger for fleets of 10,000 EVs. Therefore, increasing charging power will have a more significant impact on distribution grids, especially at the LV feeder level. For $10 \mathrm{EVs}$, moving from 3.7 to $7.4 \mathrm{kVA}$ chargers

\footnotetext{
${ }^{7}$ Coincidence factor is the ratio of simultaneous maximum demand of a group of electricity customers over the maximum demand capacity. In this case it represents the maximum share of EVs charging at the same moment.
} 
represents an increase of $66 \%$ in EV peak load, whereas for 10,000 EVs (HV/MV level) the same increase in charging power represents only a $13 \%$ in EV peak load.

More importantly, results show almost no difference in peak load for uncontrolled charging for different battery sizes and plug-in behaviors for each of the three charger power levels. This means that even though there are fewer vehicles connected every day, the peak coincidence factor of EV charging remains the same due to higher energy requirements per session. Increasing battery sizes does not modify peak load, even though it represents a higher energy consumption due to lower driving efficiency. However, the EV load shape is altered as charging shifts towards later hours due to each charging session lasting longer. This effect is higher for large-battery EVs, which is in line with results found in Dixon and Bell (2020). Therefore, current trends of increasing battery sizes make it crucial for EV grid impact studies to consider non-systematic plug-in behavior (see Appendix for the detailed EV load curves).

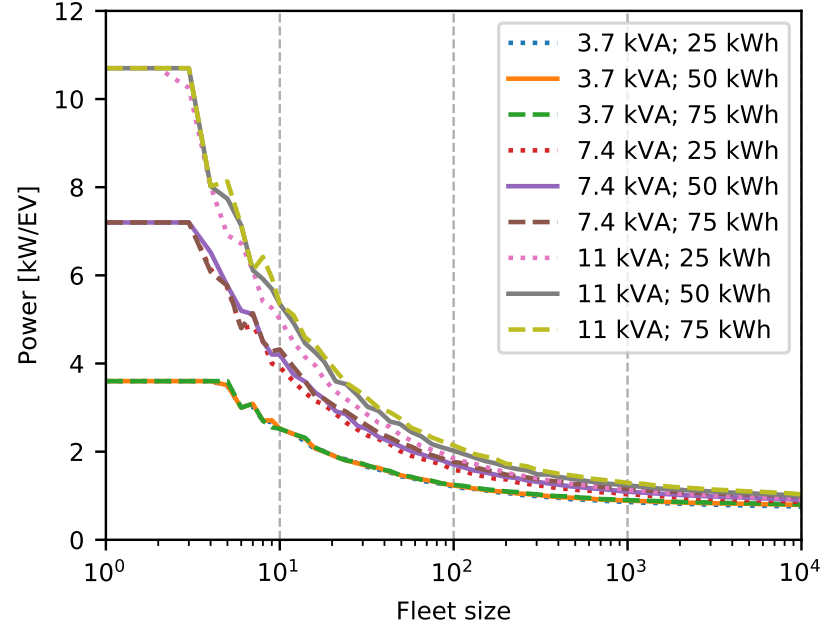

(a) Average plug-in behavior

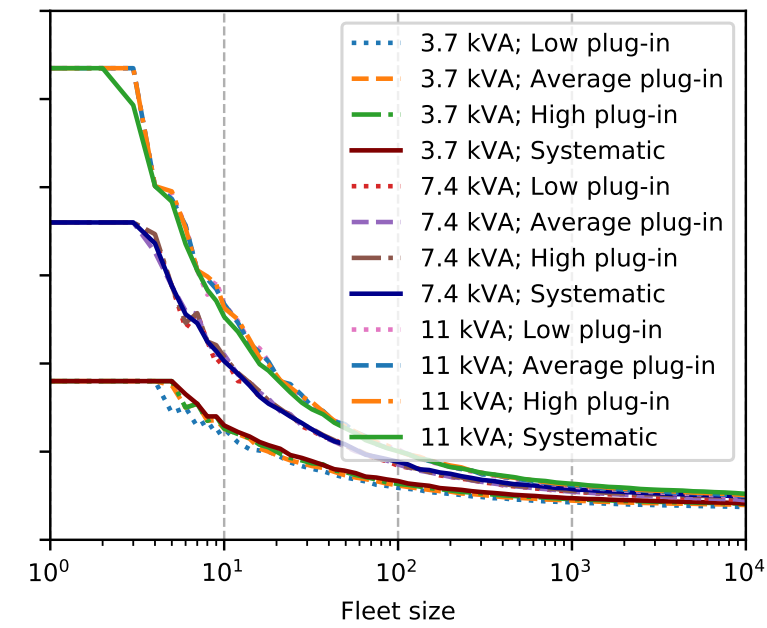

(b) $50 \mathrm{kWh}$ battery

Figure 9: Peak load for varying fleet sizes $[\mathrm{kW} / \mathrm{EV}]$ for the uncontrolled charging strategy. (a) Different battery sizes with average plug-in behavior $(\alpha=1.31)$, and (b) different plug-in behaviors with $50 \mathrm{kWh}$ battery EVs.

Widespread uncontrolled charging is unlikely to be the norm. EV users can adapt their charging strategy based on electricity tariffs to reduce their energy bills, and price-responsive (smart) charging is already possible with time-of-use tariffs such as peak/off-peak and dy- 
Table 5: Peak power per EV [kW/EV] and coincidence factor for fleets of 10, 100 and 10,000 EVs for the uncontrolled case. $50 \mathrm{kWh}$ EVs and average plug-in behavior.

\begin{tabular}{lrrrrrr} 
& \multicolumn{3}{c}{ Power $[\mathrm{kW} / \mathbf{E V}]$} & \multicolumn{3}{c}{ Coincidence factor } \\
Charger power & $\mathbf{1 0}$ & $\mathbf{1 0 0}$ & $\mathbf{1 0 , 0 0 0}$ & $\mathbf{1 0}$ & $\mathbf{1 0 0}$ & $\mathbf{1 0 , 0 0 0}$ \\
\hline $3.7 \mathrm{kVA}$ & 2.52 & 1.23 & 0.79 & $70 \%$ & $34 \%$ & $22 \%$ \\
$7.4 \mathrm{kVA}$ & 4.20 & 1.71 & 0.90 & $58 \%$ & $24 \%$ & $12 \%$ \\
$11 \mathrm{kVA}$ & 5.35 & 2.02 & 0.99 & $50 \%$ & $18 \%$ & $9 \%$ \\
\hline
\end{tabular}

namic tariffs that follow (sub) hourly market prices, as found in numerous countries (Hoarau and Perez (2018), Freitas Gomes et al. (2021)). While smart charging can benefit the (local) system by shifting load to off-peak hours, there is a risk of synchronizing EV charging in low-price periods that can create even higher congestion at the local distribution grid, as noted in Verzijlbergh et al. (2014).

Results for the smart charging case, depicted in Fig. 10, show the synchronization of EV charging at low-price periods, with a greater peak load created under this case than under the uncontrolled case. Peak load for a fleet size of 10,000 EVs and non-systematic plug-in behavior increases between $107 \%$ for $3.7 \mathrm{kVA}$ chargers and $377 \%$ for $11 \mathrm{kVA}$ chargers, with respect to the uncontrolled case (see summary in Table 5. At the LV level (between 10 to $100 \mathrm{EVs}$ ), the coincidence factor of EV charging remains high, especially for small-sized EVs which are plugged in more often.

Considering systematic (every day) plug-in behavior highly overestimates the impact of price-responsive EV charging into the grid (see bottom plots in Fig. 10), as it considers that all EVs will charge at the same moment. This may have little effect at the LV feeder level, as a high coincidence of EV charging can be expected for low numbers of EVs in all plug-in behavior cases (though not everyday). However, it has significant effects at the MV or HV level (fleet sizes above $100 \mathrm{EVs}$ ) as coincidence factors are double than those obtained for the non-systematic case. This can lead to overestimate the congestion created by EVs in the distribution grid, and wrongly estimate infrastructure reinforcement 8 . Price-responsive

\footnotetext{
${ }^{8}$ See Veldman and Verzijlbergh (2015) for an example of a smart charging impact assessment that showed high infrastructure requirements at the MV distribution level to cope with price-responsive EVs under high
} 
charging prompts a larger difference from plug-in behaviors than in the uncontrolled case, with lower peak loads for the low plug-in case, as fewer EVs are connected simultaneously, and with a greater impact of high-power chargers. However, the differences among nonsystematic cases remain low compared to the systematic case highlighting the importance of considering non-systematic plug-in behavior, even with a roughly tuned parameter, on top of getting the model parametrization correctly fine-tuned (i.e., setting the correct $\alpha$ ). We also observe a positive effect (i.e., reducing the peak load) of larger battery sizes, as lower plug-in frequency from larger EVs results in a lower coincidence of price-responsive EV charging.

Table 6: Peak load for price-responsive charging and 10,000 EV fleet. Peak power per EV [kW/EV], coincidence factor $(\mathrm{CF})$ and increase with respect to the uncontrolled case for the average plug-in and systematic cases.

\begin{tabular}{lrrrrrr}
\hline & \multicolumn{3}{c}{ Average $(\alpha=1.31)$} & \multicolumn{3}{c}{ Systematic } \\
Charger Power & Power & CF & Increase & Power & CF & Increase \\
\hline $3.7 \mathrm{kVA}$ & 1.64 & $46 \%$ & $+105 \%$ & 3.51 & $97 \%$ & $+338 \%$ \\
$7.4 \mathrm{kVA}$ & 3.27 & $45 \%$ & $+261 \%$ & 6.57 & $91 \%$ & $+630 \%$ \\
$11 \mathrm{kVA}$ & 4.73 & $44 \%$ & $+373 \%$ & 8.88 & $83 \%$ & $+788 \%$ \\
\hline
\end{tabular}

Note that even though smart charging can create higher EV peak loads than uncontrolled charging due to the synchronization of EV charging events, it does not necessarily translate into higher peak loads at the distribution or transmission system. Well-adjusted price signals can shift EV load to low-demand periods where the system can absorb the extra load, and the non-systematic plug-in behavior of users reduces the risk of creating excessive additional demand during these periods. EV grid integration studies are still needed to assess the impact of EV charging, especially at the LV distribution grid, to analyze voltage deviations and unbalances, and they should consider non-systematic plug-in behavior, as longer charging sessions can create grid issues at different timeframes, an effect that is increased with current trends of increasing battery sizes.

wind power penetration scenarios. 


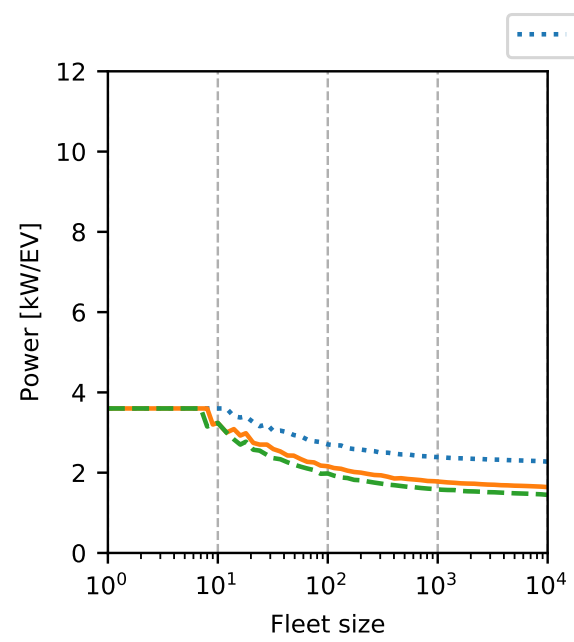

(a) Average plug-in 3.7 kVA charger

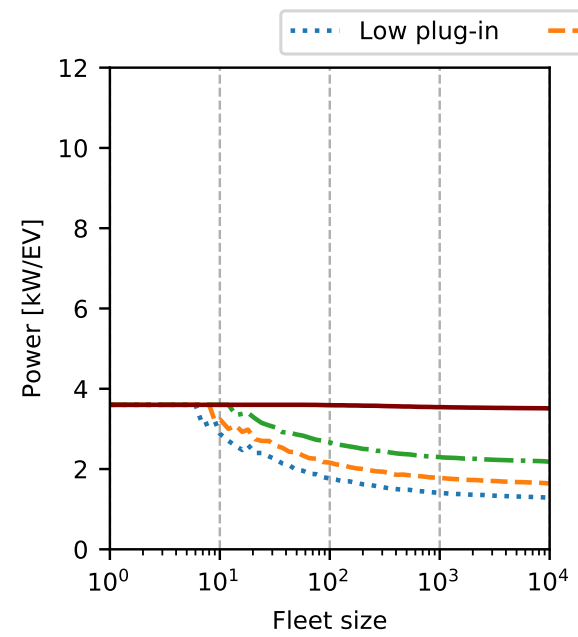

(d) $50 \mathrm{kWh}$ battery 3.7 kVA charger

\section{$25 \mathrm{kWh}$ $50 \mathrm{kWh}$ \\ $75 \mathrm{kWh}$}

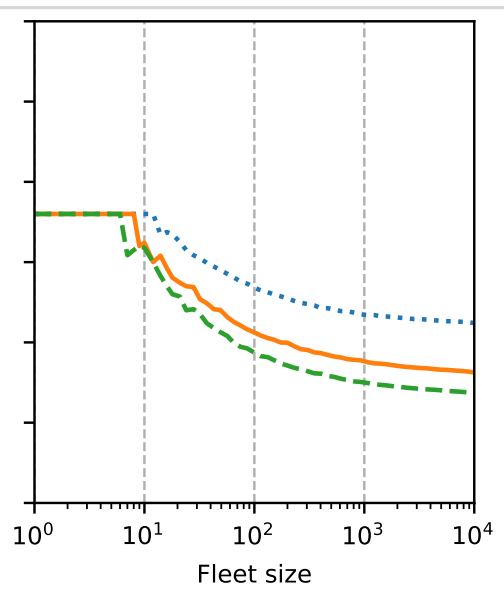

(b) Average plug-in 7.4 kVA charger

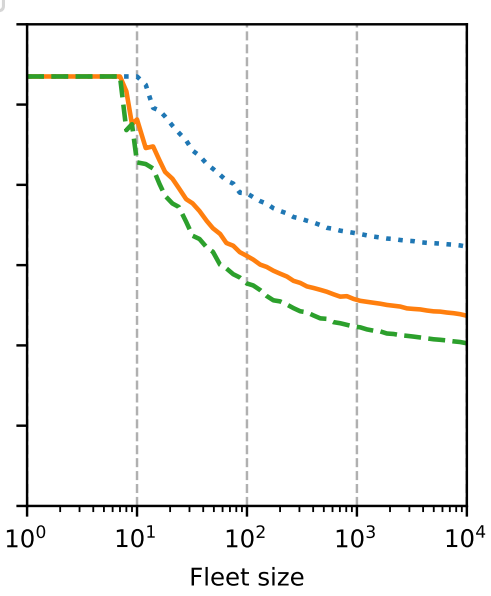

(c) Average plug-in 11 kVA charger
Average plug-in - High plug-in _ Systematic

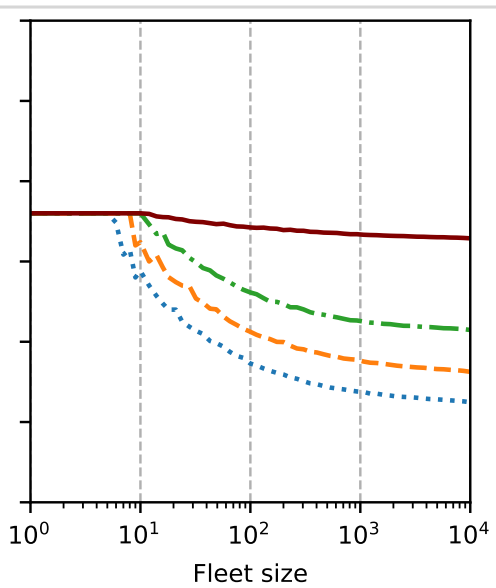

(e) 50 kWh battery 7.4 kVA charger

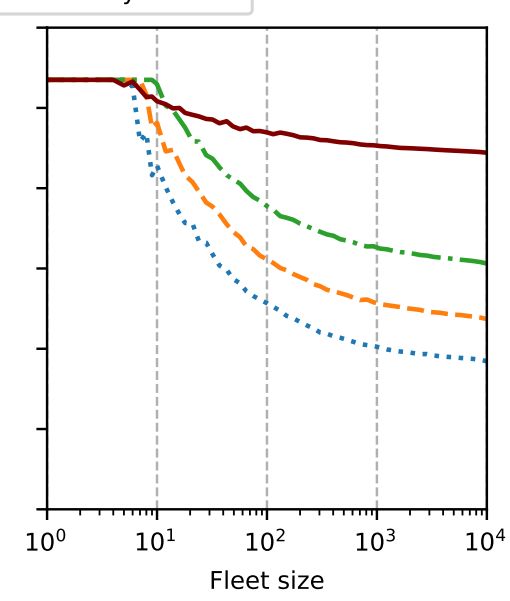

(f) $50 \mathrm{kWh}$ battery 11 kVA charger

Figure 10: Peak load for varying fleet sizes $[\mathrm{kW} / \mathrm{EV}]$ for the price-responsive charging strategy. Top: different battery sizes with average plug-in behavior $(\alpha=1.31)$. Bottom: different plug-in behaviors for $50 \mathrm{kWh}$ battery EVs. 


\subsection{Impact on flexibility potential}

As discussed in Section 1, EVs can act as flexibility resources that can help the electricity system at various levels, from optimizing the use of grid assets and deferring infrastructure reinforcements to helping the integration of renewable energies. However, to provide this flexibility, the EVs need to be connected to the grid in the first place. EV fleets with uncertain plug-in behavior may have limited participation in flexibility services that require high reliability, such as investment deferral for distribution grids (Gonzalez Venegas et al. $(2020))$.

Flexibility depends on three dimensions: time, power and energy Schlund et al. (2020). In the case of an EV charging session flexibility depends on the idle time (i.e., the time spent connected but not charging) and quantifies the time during which flexibility can be provided without affecting the user's driving needs. The flexibility that the EV will provide will also depend on the charging power (in $\mathrm{kW}$ ) and on the storage capacity (energy, in $\mathrm{kWh}$ ) of the EV. Different flexibility services have different time, power and energy requirements. Balancing services like primary frequency response are more power-based, with low energy requirements and are required all the time. In contrast, services like back-up power or peakshaving are more energy-intensive, requiring a sufficient storage capacity if V2G is considered but limited to a few hours per day.

We analyzed three indicators to assess the flexibility that can be provided by V2G-capable EV fleets from an aggregator's point of view, covering the three dimensions of flexibility: the average charging and flexible time of charging sessions (in hours); the average flexible power per EV (in kW/EV); and the average accessible storage capacity of an EV fleet (in kWh/EV).

The average duration of charging sessions and their charging and flexible times for different battery sizes and plug-in behaviors are shown in Fig. 11. The average duration of charging sessions remains constant for the different cases (10.2 hours), as it is given by the arrival and departure times of users and not for how often they plug-in, but the time spent charging depends greatly on battery size and the user's plug-in behavior. Under the systematic plug-in assumption, the average charging time per session is between 2 to 3 hours with a $3.7 \mathrm{kVA}$ charger and around 1 hour with a $7.4 \mathrm{kVA}$ charger, leaving more than 12 hours of idle time to provide flexibility. However, when considering non-systematic plug-in 
behavior, users charge less often and require more energy in each charging session, increasing the charging duration and reducing the flexible time. This effect is higher for larger battery sizes, as they tend to plug in less frequently and have higher energy requirements. For users with a $3.7 \mathrm{kVA}$ charger and battery sizes above $60 \mathrm{kWh}$, average charging times are above 5 hours (average plug-in case), thus reducing flexible time accordingly. As these indicators are average values, there may be cases where charging time exceeds connection time, thus creating the possibility that large-battery EV users will adopt high-power chargers to reduce these risks. This can be a more significant issue in countries where residential dwellings already have three-phase grid connection, such as Germany or the Netherlands, easing the installation of high-power chargers at home, unlike France or the UK where residential dwellings have primarily single-phase grid connections. Nevertheless, average flexible time remains high, at above 8 to 10 hours per charging session for most cases and battery sizes under 60 kWh, which can be ample margin to shift charging to off-peak hours or provide even a few hours of bidirectional power to the grid.



(a) 3.7 kVA charger



(b) 7.4 kVA charger



(c) 11 kVA charger

Figure 11: Average charging and flexible times of charging sessions for a 1,000 EV fleet. Arrows indicate charging time for the case systematic plug-in and flexible time for the case of non-systematic low plug-in.

The participation of aggregators in flexibility services such as frequency regulation Borne et al. (2018) or long-term local flexibility tenders Gonzalez Venegas et al. (2019), depend on the power (in $\mathrm{kW}$ or MW) that they can provide to system operators. Thus, the controllable 
power is a key metric for aggregators. The power that EV aggregators can access depends mainly on the number of EVs connected to the grid, which varies along the day, as shown in Fig. 12, As our case study refers to home charging, EVs are mostly connected during nighttime, i.e., between $8 \mathrm{pm}$ and 7 am. We computed the flexible power seen from an aggregator's perspective, shown in Fig. 13, as the average charging power of connected EVs between $10 \mathrm{pm}$ and $6 \mathrm{am}$, which is the period in with the highest share of connected EVs. Note that for V2G-capable fleets, the flexible power can provide both upwards and downwards flexibility. An aggregator that controls fleets that are systematically connected can be certain that all EVs will be available as flexibility resources, thus offering access to the full charger power of the whole EV fleet. However, when considering non-systematic plug-in behavior, fewer EVs are connected per day, and so the aggregator has a lower amount of power flexibility to control. With a fleet of $25 \mathrm{kWh}$ EVs, an aggregator will only have access to $60 \%$ of the fleet power on average, and this figure drops to less than $40 \%$ for battery sizes above $60 \mathrm{kWh}$. Therefore, large-battery EVs can present risks to flexibility aggregators, as they will have to contend with fewer EVs connected daily and less flexible time per charging session.

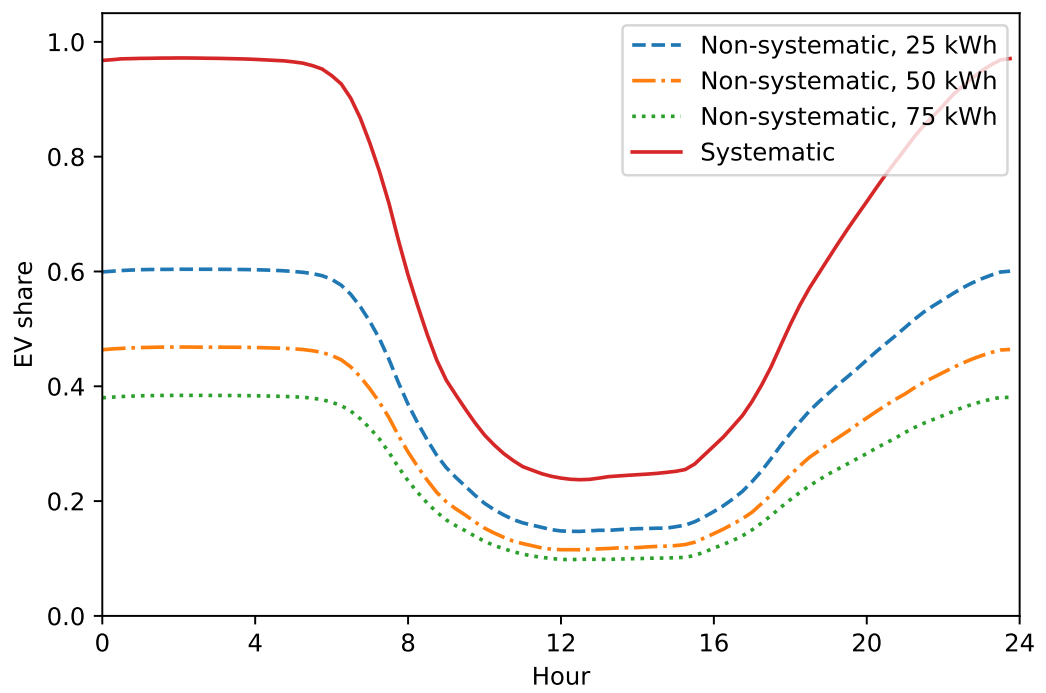

Figure 12: Average share of connected EVs along the day. Average plug-in behavior for non-systematic cases.

Finally, the flexibility that V2G-capable EVs can provide also depends on the storage 


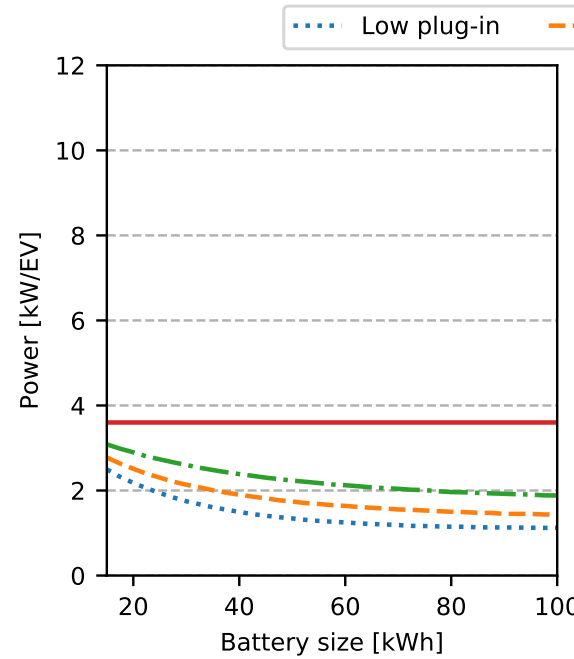

(a) 3.7 kVA charger

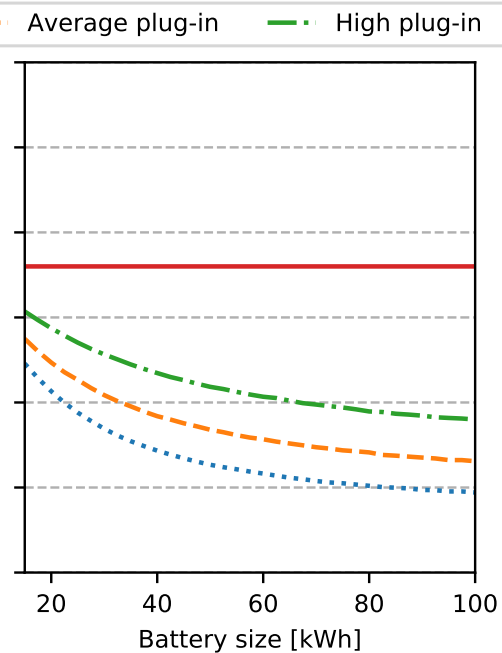

(b) 7.4 kVA charger

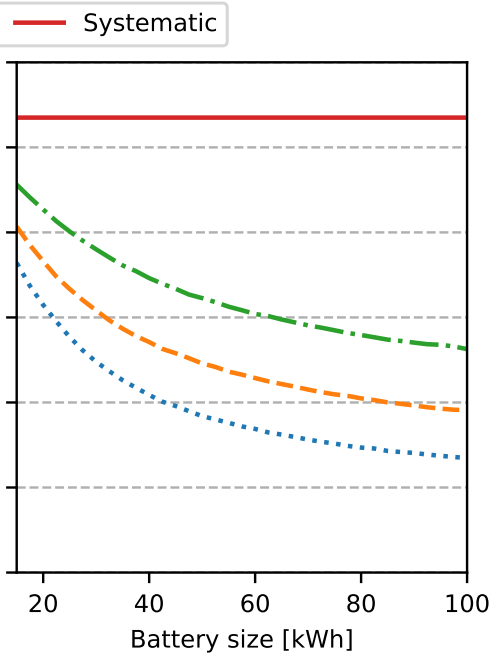

(c) 11 kVA charger

Figure 13: Average flexible power [kW/EV] during high-availability hours (10pm-6am) for a 1,000-EV fleet

capacity that they can access (i.e., the energy aspect of flexibility). To assess the flexibility storage capacity that an EV aggregator can control, we defined the accessible storage of a V2G-capable EV as the space of feasible charging trajectories, depicted in green in Fig. 14. The accessible storage of a charging session for one EV will depend on its battery size, charging power, and connection duration. The accessible storage of an EV fleet $\left(A S_{f}\right)$ is then computed as the sum of accessible storage of all EVs for an average charging period, as shown in Eq. 6, $t s_{\text {avg }}$ is the average charging session duration of 10.2 hours and $n_{\text {evs }}$ is the number of EVs in the fleet (we express this indicator in $\mathrm{kWh} / \mathrm{EV}$ to make it independent of fleet size). the number of EVs in the fleet (we express this indicator in $\mathrm{kWh} / \mathrm{EV}$ to make it independent of the fleet size).

$$
A S_{f}=\frac{\sum_{e \in E V} \int_{t} A S_{e}(t) d t}{n_{\text {evs }} \cdot t s_{\text {avg }}}
$$

The results for average accessible storage per EV for different battery sizes and plug-in behaviors, shown in Fig. 15, point to several conclusions.

First, when considering systematic plug-in behavior, which is the ideal case where EVs are plugged in every day, larger battery sizes increase the accessible storage per EV, but only up to a given battery size dependent on charger power. This means that increasing battery sizes above a certain threshold does not increase the accessible storage capacity of a 


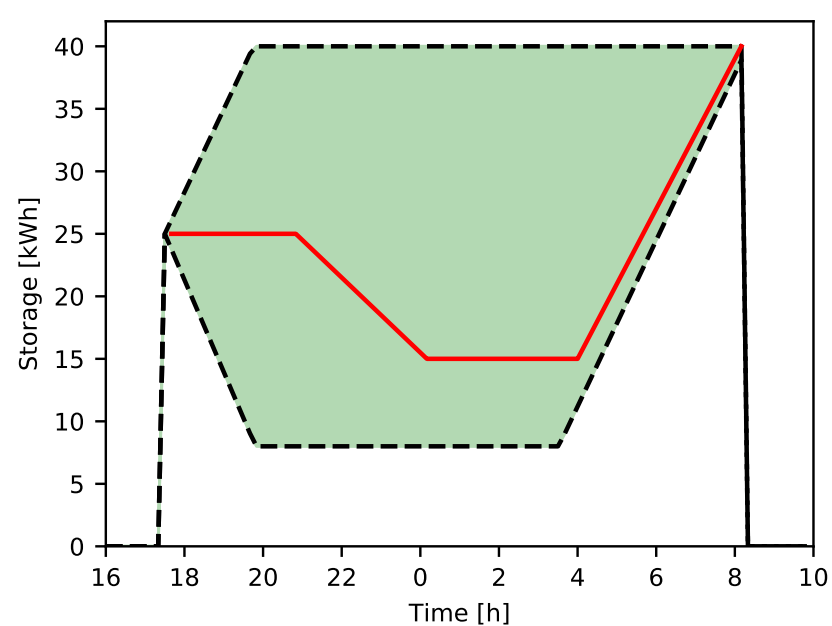

(a) $40 \mathrm{kWh}, 7,4 \mathrm{kVA}$

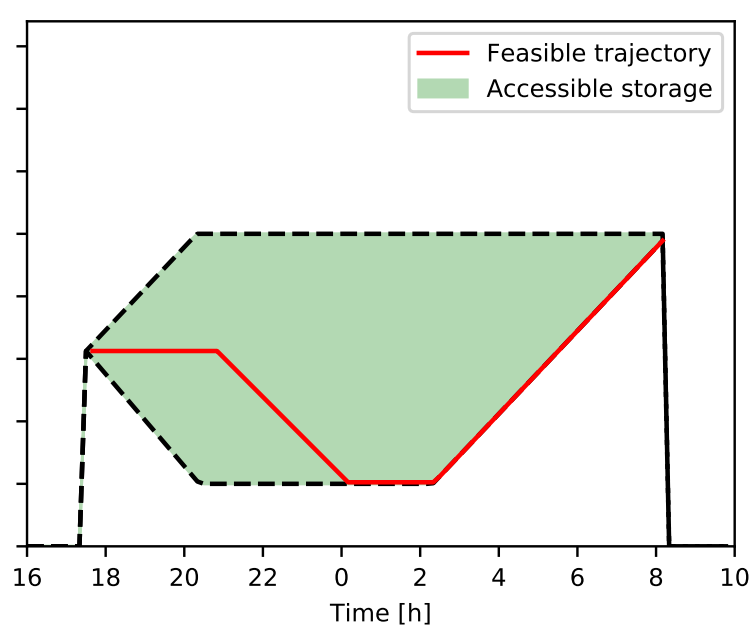

(b) $25 \mathrm{kWh}, 3.7 \mathrm{kVA}$

Figure 14: Example of the accessible storage of a charging session of a single EV $\left(A S_{e}(t)\right)$ with a feasible charging (and discharging) trajectory. (a) EV with $40 \mathrm{kWh}$ battery and $7.4 \mathrm{kVA}$ charger, and (b) EV with $25 \mathrm{kWh}$ battery and $3.7 \mathrm{kVA}$ charger. A minimum $\mathrm{SoC}$ of $20 \%$ was considered for computing the accessible storage.

fleet, as this additional storage capacity is not accessible during the charging session time $\square^{9}$ For a $3.7 \mathrm{kVA}$ charger, the maximum accessible storage is $15.7 \mathrm{kWh}$, reached with $40 \mathrm{kWh}$ batteries, which can be increased to $30.5 \mathrm{kWh}$ with $7.4 \mathrm{kVA}$ chargers, reached with battery sizes larger than $80 \mathrm{kWh}$. In both cases the accessible storage represents around 4.5 hours of bidirectional power injection to the grid. Thus, to fully access EVs' storage capabilities of large-battery EVs requires an increase in charging power. However, increasing charger power can have a significant impact on the distribution grid, as shown in Section 5.1 .

Second, when we consider non-systematic plug-in behavior, the accessible storage of the whole fleet is reduced by at least $50 \%$, as fewer EVs are connected and they have reduced flexible time. Moreover, we observe a peak in accessible storage, at around $25 \mathrm{kWh}$ for a 3.7 kVA charger, and around $60 \mathrm{kWh}$ for a $7.4 \mathrm{kVA}$ charger, after which increasing battery sizes

\footnotetext{
${ }^{9}$ For a 10 hour charging session of a $50 \mathrm{kWh}$ EV with a $7.4 \mathrm{kVA}$ charger, and disregarding charging requirements, it can, at most, discharge during 5 hours and then charge during the remaining 5 hours, having a maximum accessible storage of $37 \mathrm{kWh}$. Increasing the battery size does not provide additional flexibility.
} 
reduces accessible storage. This is due to lower plug-in rates and higher energy requirements per charging session for larger battery sizes. Therefore, increasing battery sizes can present high risks for EV aggregators wanting to offer flexibility services to the grid, as larger-battery EVs actually decrease the accessible storage. Increasing the charger power can increase the accessible storage, but this increase is much less significant than with systematic charging. Providing incentives to plug in (i.e. changing from an average plug-in behavior to a high plug-in one) can be equally or more effective in increasing accessible storage than increasing charger power.

Third, a fleet composed of small-battery EVs that is systematically connected, which can be the case for company fleets (see, for example, the Parker demonstrator project; Parker Project (2018)), can provide greater flexibility than a fleet of large-battery EVs with nonsystematic plug-in. From the results shown in Fig. 15, for 11 kVA chargers, a fleet composed of $20 \mathrm{kWh}$ EVs with systematic charging can offer greater accessible storage than a 50 or 80 kWh fleet with an average plug-in behavior.

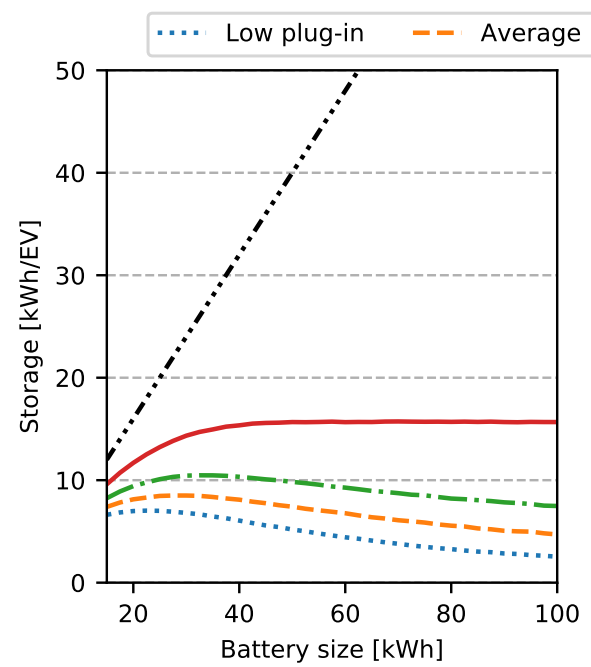

(a) 3.7 kVA charger

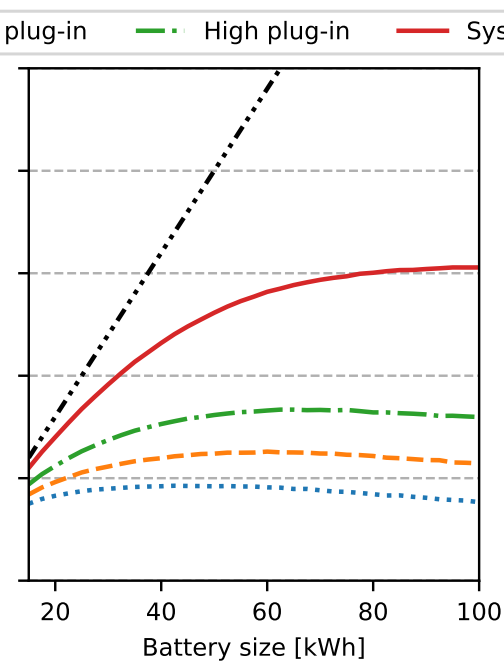

(b) 7.4 kVA charger

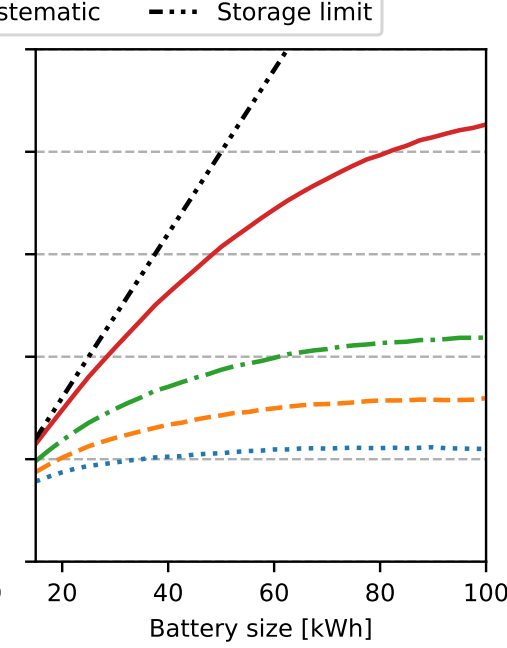

(c) 11 kVA charger

Figure 15: Average accessible storage $[\mathrm{kWh} / \mathrm{EV}]$ for a 1,000 EV fleet and for three charger power levels. Storage limit is equal to $80 \%$ of the battery size.

These results demonstrate the significance of EV users' plug-in behavior as a factor in the flexibility that can be provided to the system. EV fleets with high plug-in frequency can provide increased flexibility, both in power and energy, compared to regular EV users. To 
maximize the accessible flexibility of EV fleets, EV aggregators should provide the incentives for end-users to plug in on a regular basis.

\section{Conclusions}

The integration of a large number of EVs into the grid is likely to pose significant challenges, due to the additional demand it creates, but also significant opportunities for improved operation of electricity systems from the use of smart charging or V2G-based flexibility. To correctly assess the impact of EV integration into the grid and the flexibility that EVs can provide to the system, models should appropriately reflect EV users' real driving and charging behaviors. Studies have evidenced the fact that EV users do not plug in their vehicle every day, yet few EV grid integration studies have considered this real-world behavior pattern, and the models available present several limitations.

The objective of this work was to quantify the impact of non-systematic plug-in behavior on EV grid integration studies. To do so, an agent-based EV simulation model that considers a probabilistic plug-in decision module was developed, and the model parameters were then calibrated to match the charging behavior observed in the Electric Nation project, a largescale smart charging trial in the UK that covered a wide range of EV marks and models. Results show that our model correctly captures the heterogeneity of users' charging preferences and can be used to generate load curves for a wide array of EV conditions, including different battery sizes and driving patterns. On average, users tend to charge their vehicle between 2 to 3 times per week, with large-battery EVs having reduced plug-in frequency and higher energy requirements per charging session.

We evaluated the impact of the non-systematic plug-in behavior of EV users charging at home through two aspects: the peak load that EVs generate at different levels of the grid, and the flexibility potential that can be offered during charging sessions. Results show that it is crucial to factor in non-systematic plug-in behavior in order to correctly assess EV charging at the distribution level, especially considering the current trend towards increasing battery sizes, for both uncontrolled and price-responsive smart charging. For price-responsive EV charging, considering only systematic charging (i.e., every day) significantly overestimates the impact of EV load synchronization at low-price hours. Increasing battery sizes has a positive 
effect on peak load (i.e. reducing peak load), as their lower charging frequency reduces the coincidence of EV charging, but at the cost of longer charging sessions or increased charger power. Results also highlight the significant impact of EVs on LV grids, where clusters of tens of EVs can present high coincidence factors that may create risks for grid stability, and these effects can be exacerbated by increasing charging power. This impact gets reduced on higher-voltage levels where the diversity of connection start time and charging requirements of a high number of EVs reduces the coincidence factor of EV charging.

Our results concerning the flexibility potential of V2G-capable EV fleets based on nonsystematic plug-in behavior show a significant reduction in accessible flexibility for EV aggregators, especially for larger battery sizes as they have lower plug-in rates, less flexible time of charging sessions, and reduced accessible storage capacity. Accessible storage capacity is reduced by at least 50\% when considering an average plug-in rate (based on observations of the Electric Nation trial) compared to a systematic plug-in behavior. Moreover, we found that accessible storage reaches a maximum value for a given charger power configuration, even under the case of systematic charging. Increasing battery sizes above $20-30 \mathrm{kWh}$ with a $3.7 \mathrm{kVA}$ charger or above $60 \mathrm{kWh}$ with a $7.4 \mathrm{kVA}$ charger does not provide any additional flexibility to the system. On the contrary, increasing battery sizes may reduce the amount of accessible flexibility for regular users fleets. One route to cope with this reduction of flexibility is to increase the charger power level, but at the expense of creating greater impacts on distribution grids from EV charging. Thus, a trade-off appears for increasing charging power between additional flexibility and higher grid impacts.

This study can provide important insights to grid planners, flexibility aggregators, regulators and car manufacturers. In particular, we show that flexibility aggregators who focus on reliable fleets that can be plugged in every day, such as company fleets, can significantly increase the flexibility they can harvest. Flexibility aggregators should also provide incentives to plug-in or identify users with aligned charging preferences to maximize their flexibility portfolio.

Results hint that V2G-based flexibility through aggregators is more likely to be developed in professional-user contexts where company fleets can have higher plug-in reliability and more consistent driving and charging patterns, than for private users where driving and 
charging patterns are less consistent. Consequently, the volume of accessible flexibility coming from private users, both in energy and power, might be less than expected. However, the development of behind-the-meter flexibility (Vehicle-to-Home or Vehicle-to-Building) can still present an interest to private users and should be considered as a potential lead for end-customer flexibility development.

Finally, with increasing EV adoption, the availability of new datasets could improve and better calibrate plug-in decision models such as the one presented in this work and consider user patterns in different countries or demographic conditions, including changes in mobility patterns. The study and modeling of how users will react to incentives to plug-in will be of high interest.Further work should be carried out to understand user charging choices and EV usages. Weekly (e.g., is there a preferred day for charging?), seasonal or event-driven patterns should be identified and analyzed, along with the impact of the availability of charging opportunities (at work, commercial centers, public charging), as they may affect EV charging patterns. Identifying and categorizing user driving and charging behaviors and their responses to plug-in incentives could help drive the development of flexibility offers around user's charging preferences.

\section{CRediT authorship contribution statement}

Felipe Gonzalez Venegas: Conceptualization, Data Curation, Methodology, Investigation, Software, Writing - Original Draft, Writing - Review \& Editing, Visualization. Marc Petit: Conceptualization, Writing - Review \& Editing, Supervision, Funding Acquisition. Yannick Perez: Conceptualization, Writing - Review \& Editing, Supervision, Funding acquisition.

\section{Acknowledgements}

This research is supported by the Chair "Hybrid Technologies and Electromobility Economy", called the Armand Peugeot Chair, led by CentraleSupélec and the ESSEC and sponsored by Stellantis, and funded by the ANRT under 'CIFRE' contract n²018/0031. 


\section{Appendix}

\subsection{Homogeneous EV model calibration}

The charging behavior indicators for an homogeneous case (with all users of the same EV group having the same $\alpha$ value), are depicted in Fig. 16. They exhibit the same trends observed in the Electric Nation trial but with no dispersion in user charging choices and a linear regression model between driven distances and charging frequency that differs significantly from the trial.

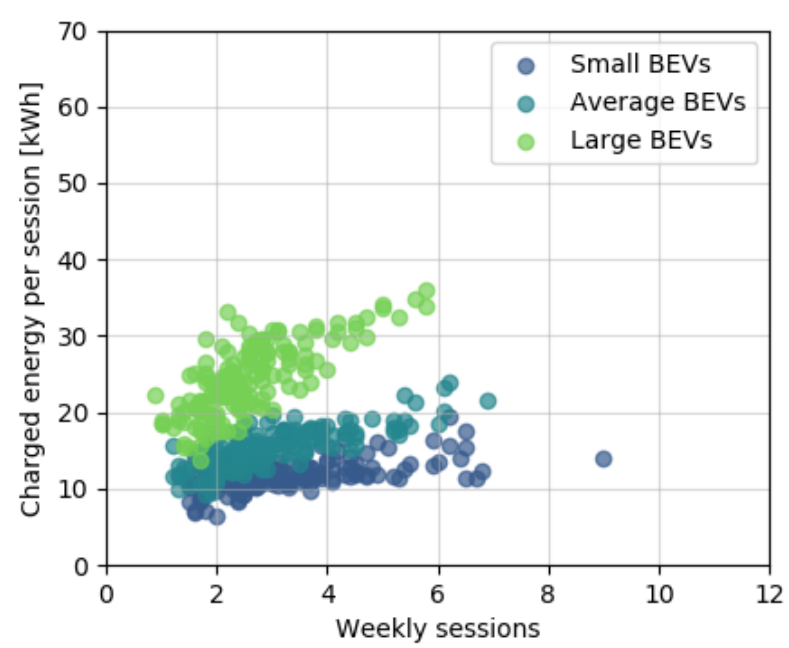

(a)

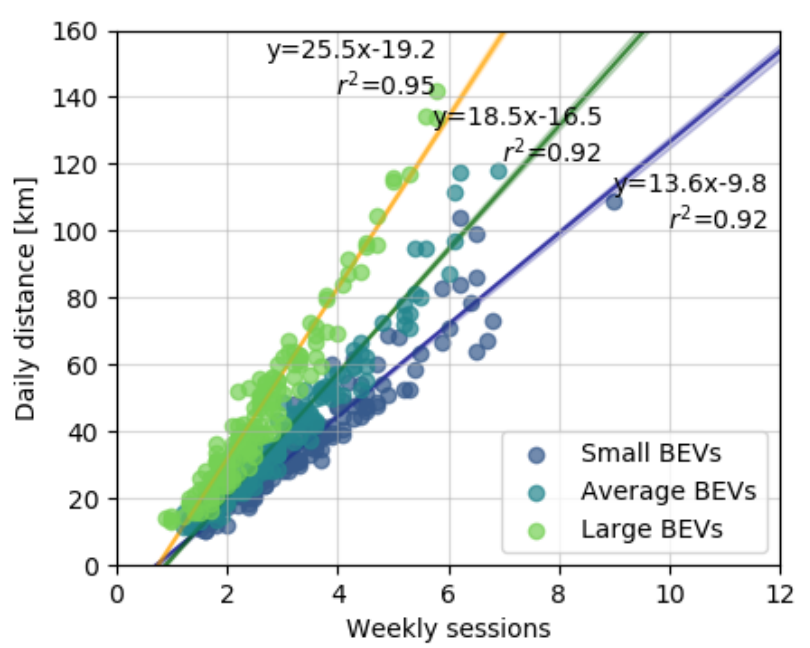

(b)

Figure 16: Charging behavior indicators for homogeneous $\alpha$ simulation: (a) Average charged energy per session and (b) daily distance driven according to weekly charging sessions. Each point corresponds to an EV user. Panel (b) includes linear regressions between weekly charging sessions and daily distance for small and large EVs, shaded areas corresponding to the confidence interval at $95 \%$ of the linear regression. 


\subsection{EV load curves}


--- Non-systematic — Systematic

Figure 17: EV charging load curves for systematic and average non-systematic plug-in behavior $(\alpha=1.31)$. Uncontrolled chargigng for 20-EV fleets with $7.4 \mathrm{kVA}$ chargers. Central lines plot average EV demand, and shaded areas show the variability of EV demand. 

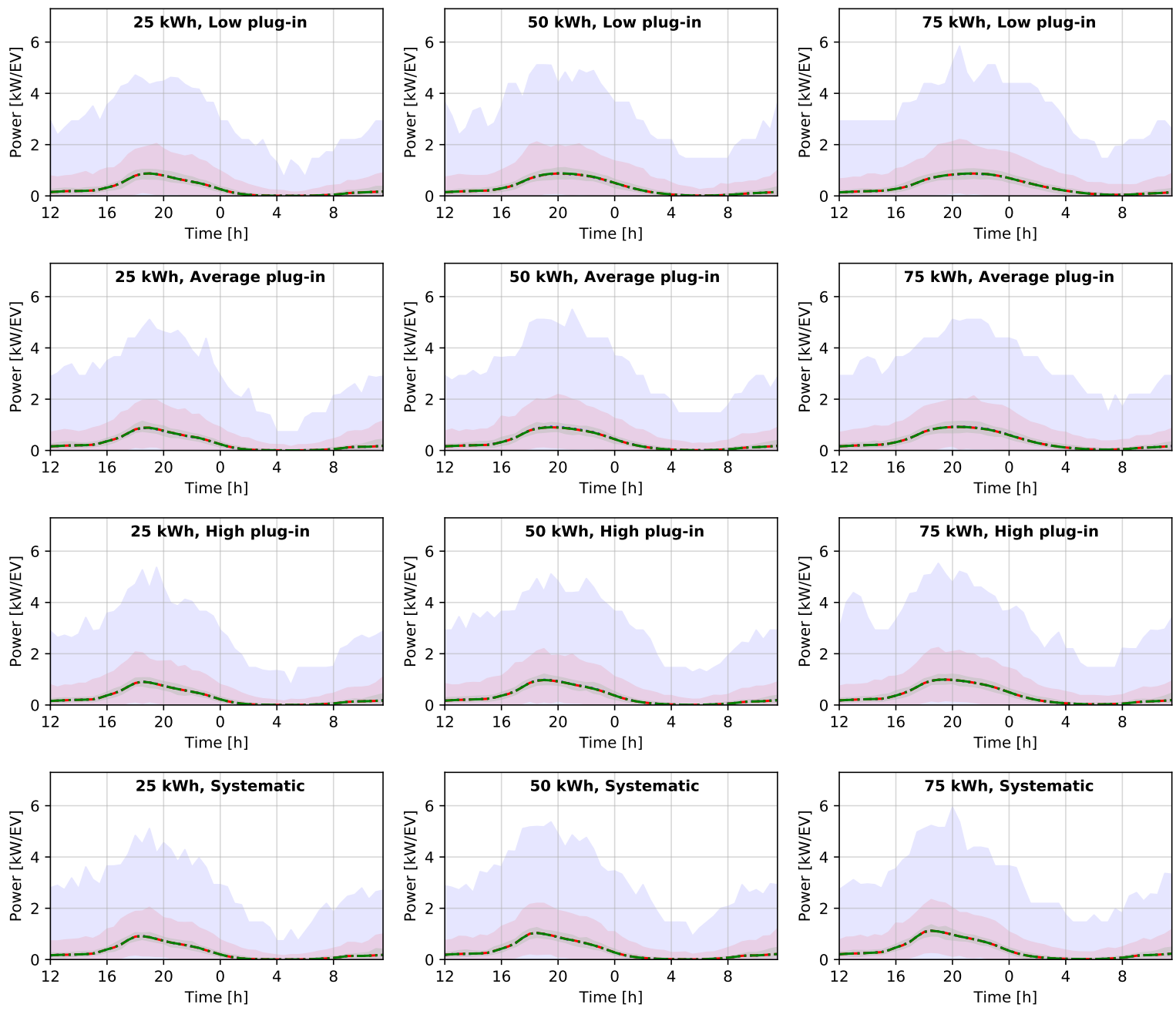

… $10 \mathrm{EVs} \quad---100 \mathrm{EVs} \quad-.-1000 \mathrm{EVs}$

Figure 18: Weekday EV charging load curves $[\mathrm{kW} / \mathrm{EV}]$ for combinations of battery sizes, plug-in behavior profiles and fleet sizes. Uncontrolled charging with $7.4 \mathrm{kVA}$ chargers. Central lines plot average EV demand, and shaded areas show the variability of $\mathrm{EV}$ demand. 


\section{References}

European Environment Agency, 2020, Greenhouse gas emissions from transport in Europe, Accessed: 2021-03-15. URL: https://www.eea.europa. eu/data-and-maps/indicators/transport-emissions-of-greenhouse-gases/ transport-emissions-of-greenhouse-gases-12.

United States Environmental Protection Agency, U.S. Inventory of Greenhouse Gas Emissions and Sinks. 1990-2018, Technical Report, 2020.

International Energy Agency, Global EV Outlook 2020, Technical Report, 2020.

EV-Volumes - The Electric Vehicle World Sales Database, 2021. Accessed: 2021-03-20. URL: https://www.ev-volumes.com/.

F. Gonzalez Venegas, M. Petit, Y. Perez, Active integration of electric vehicles into distribution grids: barriers and frameworks for flexibility services, 2021.

A. W. Thompson, Y. Perez, Vehicle-to-Everything (V2X) energy services, value streams, and regulatory policy implications, Energy Policy 137 (2020) 111136. doi:10.1016/j.enpol. 2019.111136.

Western Power Distribution, Electric Nation Customer Trial Final Report, Technical Report, 2019.

J. R. Helmus, M. H. Lees, R. van den Hoed, A data driven typology of electric vehicle user types and charging sessions, Transportation Research Part C: Emerging Technologies 115 (2020) 102637. doi:10.1016/j.trc.2020.102637.

F. Salah, J. P. Ilg, C. M. Flath, H. Basse, C. v. Dinther, Impact of electric vehicles on distribution substations: A Swiss case study, Applied Energy 137 (2015) 88-96. URL: https://www.sciencedirect.com/science/article/pii/S0306261914010393. doi:10. $1016 / \mathrm{j}$. apenergy .2014.09.091. 
E. Veldman, R. A. Verzijlbergh, Distribution grid impacts of smart electric vehicle charging from different perspectives, IEEE Transactions on Smart Grid 6 (2015) 333-342. doi:10. 1109/TSG. 2014.2355494.

M. Muratori, Impact of uncoordinated plug-in electric vehicle charging on residential power demand, Nature Energy (2018). doi:10.1038/s41560-017-0074-z.

C. Guo, K. Zhu, C. Chen, X. Xiao, Characteristics and effect laws of the large-scale electric Vehicle's charging load, eTransportation 3 (2020) 100049. doi:10.1016/j.etran.2020. 100049 .

N. Leemput, F. Geth, J. Van Roy, J. Büscher, J. Driesen, Reactive power support in residential LV distribution grids through electric vehicle charging, Sustainable Energy, Grids and Networks 3 (2015) 24-35. URL: http://linkinghub.elsevier.com/retrieve/pii/ S2352467715000375, doi:10.1016/j.segan.2015.05.002.

C. Gaete-Morales, H. Kramer, W.-P. Schill, A. Zerrahn, An open tool for creating batteryelectric vehicle time series from empirical data - emobpy (2020). URL: http://arxiv . org/abs/2005.02765.

A. Bartolini, G. Comodi, D. Salvi, P. A. Østergaard, Renewables self-consumption potential in districts with high penetration of electric vehicles, Energy 213 (2020) 118653. doi:10. $1016 / j$.energy . 2020.118653.

O. Borne, Y. Perez, M. Petit, Market integration or bids granularity to enhance flexibility provision by batteries of electric vehicles, Energy Policy 119 (2018) 140-148. URL: https://www.sciencedirect.com/science/article/pii/S0301421518302350, doi:10. $1016 /$ j.enpol.2018.04.019.

L. Calearo, M. Marinelli, Profitability of Frequency Regulation by Electric Vehicles in Denmark and Japan Considering Battery Degradation Costs, World Electric Vehicle Journal 11 (2020) 48. URL: https://www.mdpi.com/2032-6653/11/3/48. doi:10.3390/ wevj11030048. 
R. Philipsen, T. Brell, W. Brost, T. Eickels, M. Ziefle, Running on empty - Users' charging behavior of electric vehicles versus traditional refueling, Transportation Research Part F: Traffic Psychology and Behaviour 59 (2018) 475-492. doi:10.1016/j.trf.2018.09.024.

S. Zoepf, D. MacKenzie, D. Keith, W. Chernicoff, Charging Choices and Fuel Displacement in a Large-Scale Demonstration of Plug-In Hybrid Electric Vehicles, Transportation Research Record: Journal of the Transportation Research Board 2385 (2013) 1-10. URL: http://journals.sagepub.com/doi/10.3141/2385-01, doi 10.3141/2385-01.

J. Schäuble, T. Kaschub, A. Ensslen, P. Jochem, W. Fichtner, Generating electric vehicle load profiles from empirical data of three EV fleets in Southwest Germany, Journal of Cleaner Production 150 (2017) 253-266. URL: https://www.sciencedirect.com/ science/article/pii/S0959652617303761. doi:10.1016/J . JCLEPRO.2017.02.150.

X. H. Sun, T. Yamamoto, T. Morikawa, Charge timing choice behavior of battery electric vehicle users, Transportation Research Part D: Transport and Environment 37 (2015) 97-107. doi:10.1016/j.trd.2015.04.007.

N. Daina, A. Sivakumar, J. W. Polak, Electric vehicle charging choices: Modelling and implications for smart charging services, Transportation Research Part C: Emerging Technologies 81 (2017) 36-56. URL: http://dx.doi.org/10.1016/j.trc.2017.05.006. doi $10.1016 / j . \operatorname{trc} .2017 .05 .006$.

T. Franke, J. F. Krems, Understanding charging behaviour of electric vehicle users, Transportation Research Part F: Traffic Psychology and Behaviour 21 (2013) 75-89. URL: https://www.sciencedirect.com/science/article/abs/pii/ S1369847813000776, doi:10.1016/J.TRF.2013.09.002.

RTE, Enjeux du développement de l'électromobilité pour le système électrique, Technical Report, 2019.

L. Calearo, A. Thingvad, K. Suzuki, M. Marinelli, Grid Loading Due to EV Charging Profiles Based on Pseudo-Real Driving Pattern and User Behavior, IEEE Transactions on Transportation Electrification 5 (2019) 683-694. doi:10.1109/TTE.2019.2921854. 
J. Bollerslev, P. B. Andersen, T. V. Jensen, M. Marinelli, A. Thingvad, L. Calearo, T. Weckesser, Coincidence Factors for Domestic EV Charging from Driving and Plugin Behavior, IEEE Transactions on Transportation Electrification (2021) 1-1. doi:10. 1109/TTE.2021.3088275.

A. González-Garrido, A. Thingvad, H. Gaztañaga, M. Marinelli, Full-scale electric vehicles penetration in the Danish Island of Bornholm - Optimal scheduling and battery degradation under driving constraints, Journal of Energy Storage 23 (2019) 381-391. doi: $10.1016 /$ j . est . 2019.03.025.

A. Bouallaga, B. Doumbia, Stochastic Electric Vehicle Load Modeling for HV/MV Substation Constraint Assessment, in: 25th International Conference on Electricity Distribution (CIRED 2019), Madrid, 2019, pp. 3-6.

D. Fischer, A. Harbrecht, A. Surmann, R. McKenna, Electric vehicles' impacts on residential electric local profiles - A stochastic modelling approach considering socioeconomic, behavioural and spatial factors, Applied Energy 233-234 (2019) 644-658. doi:10.1016/j. apenergy . 2018.10.010.

J. Dixon, P. B. Andersen, K. Bell, C. Træholt, On the ease of being green: An investigation of the inconvenience of electric vehicle charging, Applied Energy 258 (2020) 114090. doi:10.1016/j . apenergy.2019.114090.

J. Dixon, K. Bell, Electric vehicles: Battery capacity, charger power, access to charging and the impacts on distribution networks, eTransportation 4 (2020) 100059. doi:10.1016/j. etran.2020.100059.

J. Dixon, W. Bukhsh, C. Edmunds, K. Bell, Scheduling electric vehicle charging to minimise carbon emissions and wind curtailment, Renewable Energy 161 (2020) 1072-1091. doi:10. $1016 / j$.renene.2020.07.017.

F. Gonzalez Venegas, M. Petit, Y. Perez, Impact of Non-Systematic Electric Vehicle Charging Behaviour on a Distribution Substation, in: Proceedings of 2019 IEEE 
PES Innovative Smart Grid Technologies Europe, ISGT-Europe 2019, Bucharest, 2019. doi:10.1109/ISGTEurope.2019.8905710.

F. Gonzalez Venegas, M. Petit, Y. Perez, Quantifying the participation of EV fleets in local flexibility tenders, in: Proc. of CIRED 2020 Berlin Workshop, Berlin, 2020.

J. Quirós-Tortós, L. F. Ochoa, B. Lees, A statistical analysis of EV charging behavior in the UK, in: 2015 IEEE PES Innovative Smart Grid Technologies Latin America, ISGT LATAM 2015, Institute of Electrical and Electronics Engineers Inc., 2016, pp. 445-449. doi:10.1109/ISGT-LA.2015.7381196.

M. Neaimeh, R. Wardle, A. M. Jenkins, J. Yi, G. Hill, P. F. Lyons, Y. Hübner, P. T. Blythe, P. C. Taylor, A probabilistic approach to combining smart meter and electric vehicle charging data to investigate distribution network impacts, Applied Energy 157 (2015) 688-698. URL: https://www.sciencedirect.com/science/article/ pii/S0306261915001944. doi:10.1016/j.apenergy.2015.01.144

D. Boston, A. Werthman, Plug-in vehicle behaviors: An analysis of charging and driving behavior of Ford plug-in electric vehicles in the real world, World Electric Vehicle Journal 8 (2016) 916-925. doi:10.3390/wevj8040926.

H. Lin, K. Fu, Y. Wang, Q. Sun, H. Li, Y. Hu, B. Sun, R. Wennersten, Characteristics of electric vehicle charging demand at multiple types of location - Application of an agentbased trip chain model, Energy 188 (2019) 116122. doi:10.1016/j .energy.2019.116122.

C. Marmaras, E. Xydas, L. Cipcigan, Simulation of electric vehicle driver behaviour in road transport and electric power networks, Transportation Research Part C: Emerging Technologies 80 (2017) 239-256. doi:10.1016/j.trc.2017.05.004.

P. Olivella-Rosell, R. Villafafila-Robles, A. Sumper, J. Bergas-Jané, Probabilistic AgentBased Model of Electric Vehicle Charging Demand to Analyse the Impact on Distribution Networks, Energies 8 (2015) 4160-4187. URL: http://www.mdpi.com/1996-1073/8/5/ 4160. doi:10.3390/en8054160. 
Western Power Distribution, 2019, Electric Nation Data, Accessed: 2020-10-12. URL: https: //www. westernpower.co.uk/electric-nation-data

M. Weiss, K. C. Cloos, E. Helmers, Energy efficiency trade-offs in small to large electric vehicles, Environmental Sciences Europe 32 (2020) 46. URL: https://enveurope.springeropen.com/articles/10.1186/s12302-020-00307-8. doi:10.1186/s12302-020-00307-8.

O. Borne, Vehicle-To-Grid and Flexibility for Electricity Systems: from Technical Solutions to Design of Business Models, Ph.D. thesis, Université Paris-Saclay, 2019.

J. Van Roy, Electric vehicle charging integration in buildings Local charging coordination and DC grids, Ph.D. thesis, KU Leuven, Leuven, 2015.

Department for Transport, 2020, Vehicle mileage and occupancy - GOV.UK, Accessed: 2021-06-10. URL: https://www.gov.uk/government/statistical-data-sets/ nts09-vehicle-mileage-and-occupancy.

Committee on Climate Change, The Sixth Carbon Budget. The UK's path to Net Zero, Technical Report, 2020. URL: www.theccc.org.uk/publications.

A. Bigo, Les transports face au défi de la transition énergétique. Explorations entre passé et avenir, technologie et sobriété, accélération et ralentissement, Ph.D. thesis, Institut Polytechnique de Paris, 2020. URL: https://tel.archives-ouvertes.fr/tel-03082127.

Q. Hoarau, Y. Perez, Interactions between electric mobility and photovoltaic generation: A review, Renewable and Sustainable Energy Reviews 94 (2018) 510-522. URL: https://www.sciencedirect.com/science/article/pii/S1364032118304751. doi:10. $1016 / j . r s e r .2018 .06 .039$.

I. S. Freitas Gomes, Y. Perez, E. Soumalainen, Rate design with distributed energy resources and electric vehicles : a Californian case study, EUI Working Papers (2021). URL: https: //fsr.eui.eu/publications/?handle=1814/69861. 
R. A. Verzijlbergh, L. J. De Vries, Z. Lukszo, Renewable energy sources and responsive demand. Do we need congestion management in the distribution grid?, IEEE Transactions on Power Systems 29 (2014) 2119-2128. URL: http://ieeexplore.ieee.org/document/ 6730962/, doi:10.1109/TPWRS.2014.2300941.

J. Schlund, M. Pruckner, R. German, FlexAbility - Modeling and Maximizing the Bidirectional Flexibility Availability of Unidirectional Charging of Large Pools of Electric Vehicles, in: e-Energy 2020 - Proceedings of the 11th ACM International Conference on Future Energy Systems, Association for Computing Machinery, Inc, 2020, pp. 121-132. doi: $10.1145 / 3396851.3397697$.

F. Gonzalez Venegas, M. Petit, Y. Perez, Can DERs fully participate in emerging local flexibility tenders?, in: 16th International Conference on the European Energy Market, EEM, volume 2019-Septe, Ljubljana, 2019. doi:10.1109/EEM. 2019.8916343.

Parker Project, Parker Project Factsheet, Technical Report, 2018. URL: www. parker-project.com. 